Supporting Information

Modification of Natural Proanthocyanidin Oligomers and Polymers via Chemical Oxidation in Alkaline Conditions

Iqbal Bin Imran, Maarit Karonen, Juha-Pekka Salminen and Marica T. Engström*

Natural Chemistry Research Group, Department of Chemistry, University of Turku, FI-20014 Turku, Finland

*Corresponding author: Marica T. Engström, E-mail: mtengs@utu.fi, Phone: +358 294503168 
Figure S1. UHPLC-DAD profiles $(\lambda=280 \mathrm{~nm})$ before and after oxidation of the proanthocyanidin containing 102 studied plant samples. The upper panels show the non-oxidized samples and the lower panels the oxidized samples. Each panels X-axis refer to retention time (min) and Y-axis refer to intensity (AU). Sample numbers refer to Table 1.

1. Viburnum tinus
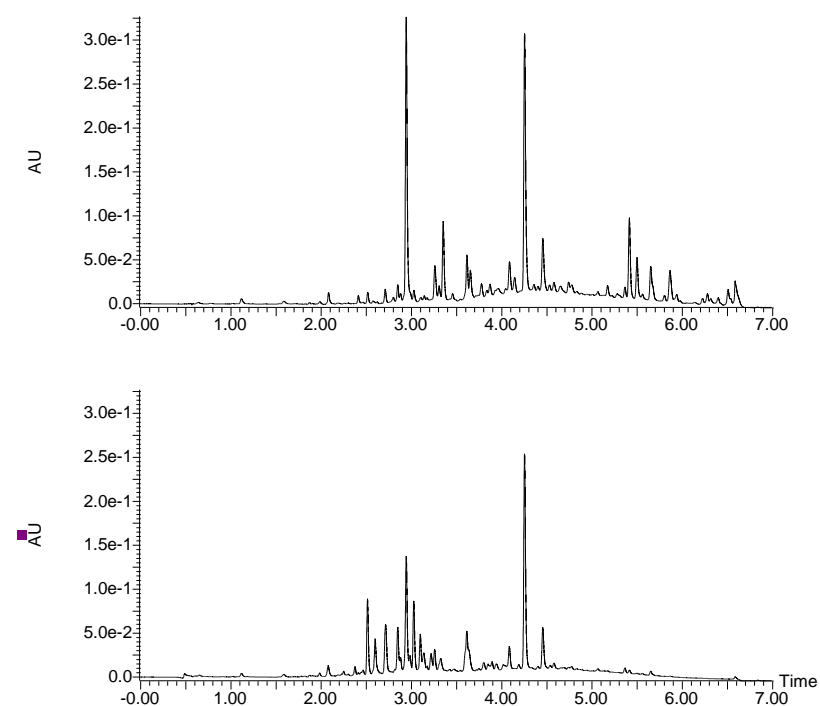

3. Aglaonema commutatum var.maculatum
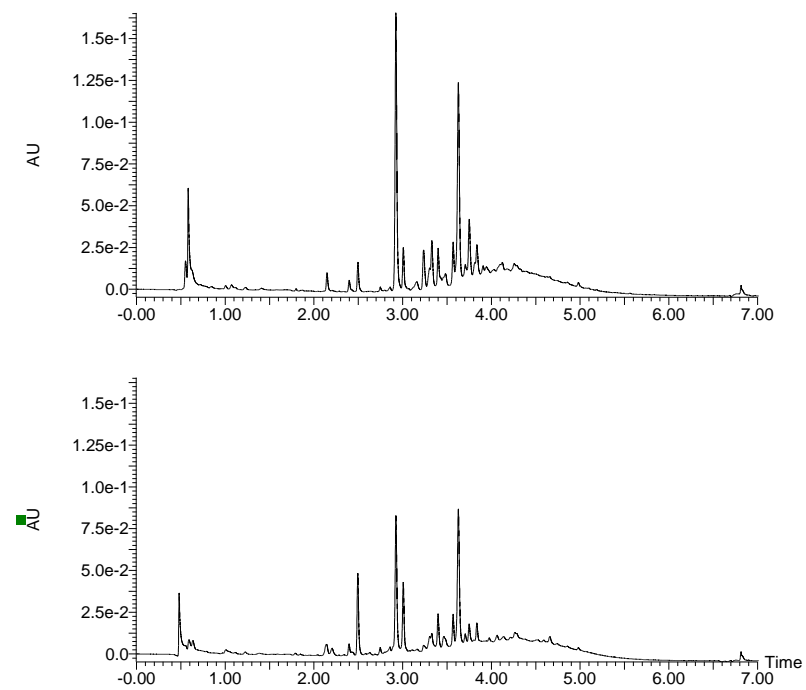

2. Mandevilla splendens
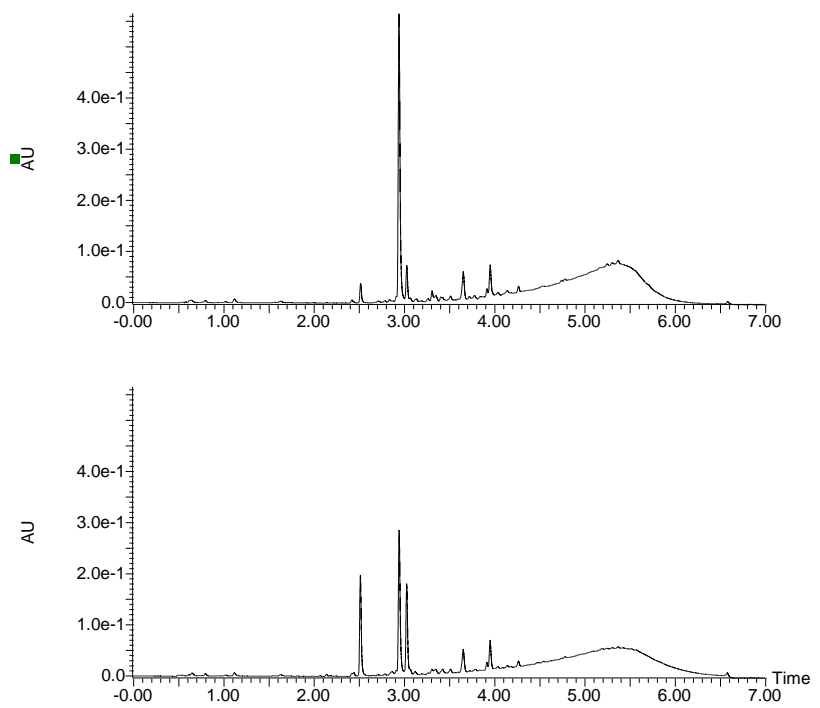

4. Aglaonema crispum
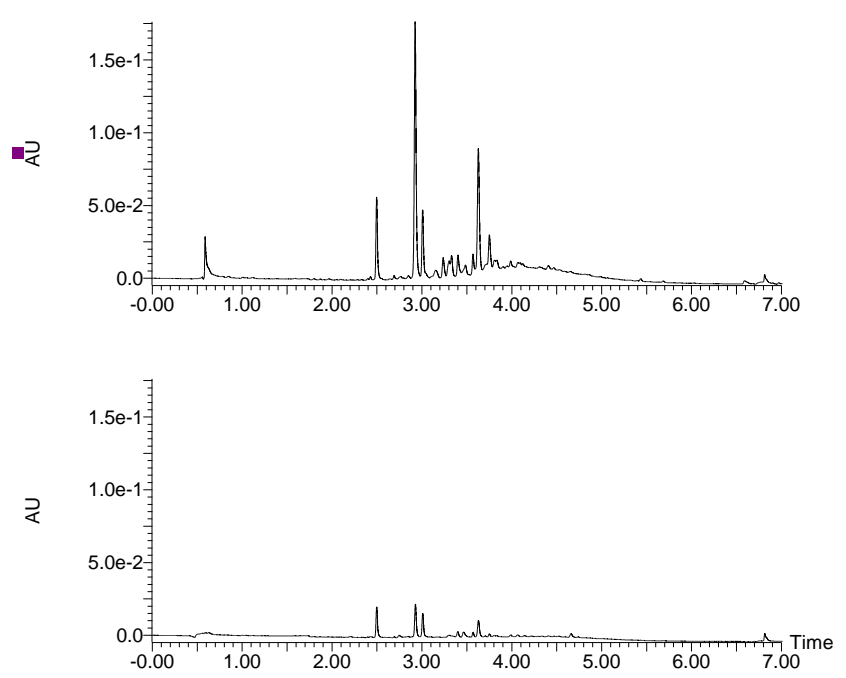


\section{Aglaonema treubii}
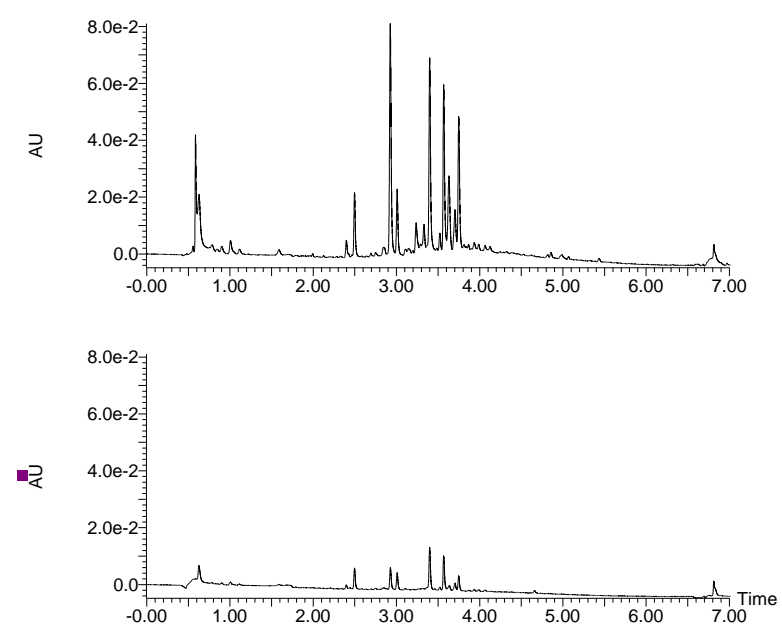

\section{Wollemia nobilis}
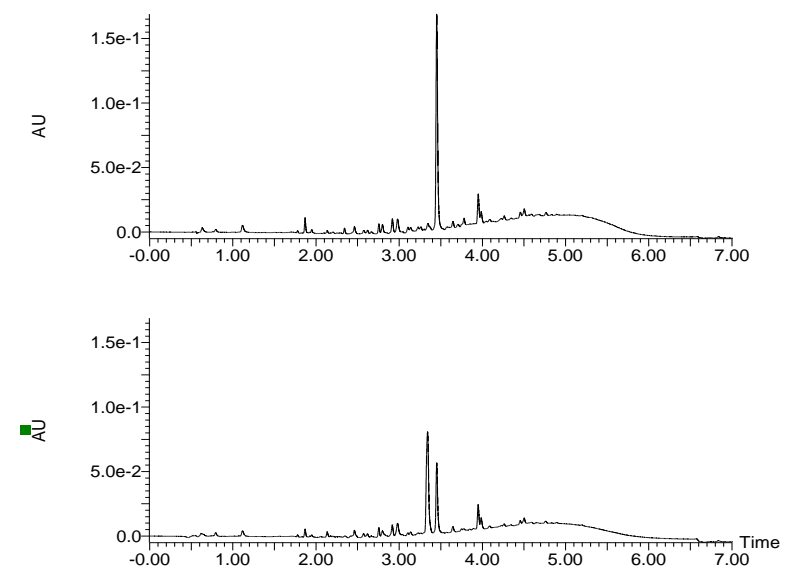

\section{Dianella intermedia}
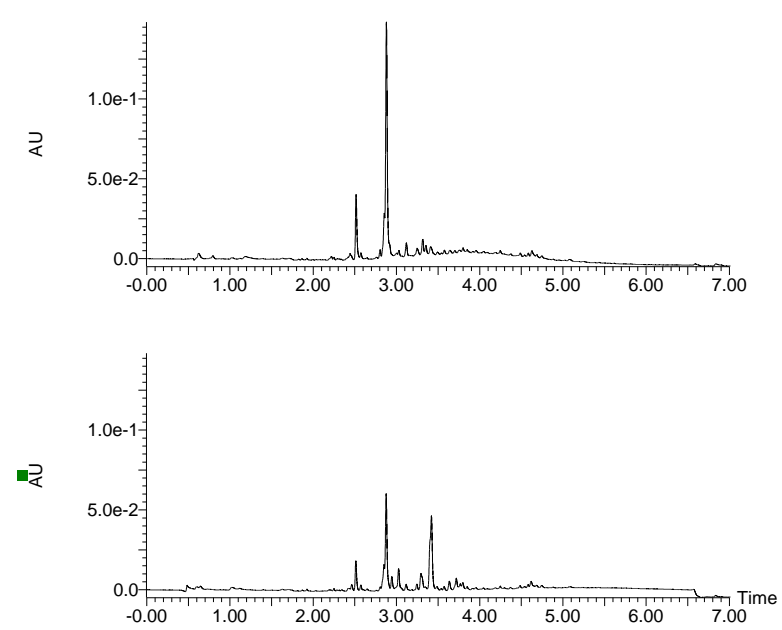

\section{Araucaria bidwillii}
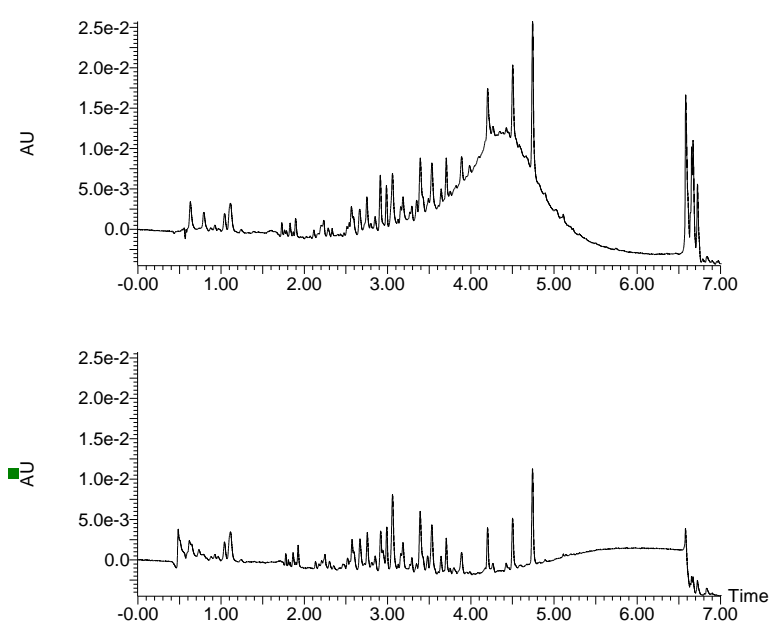

8. Dianella ensifolia
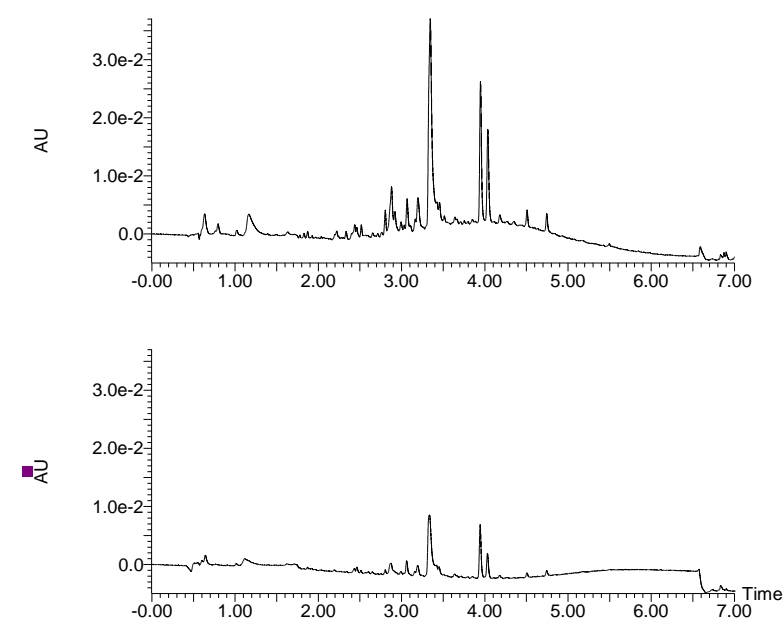

10. Impatiens repens
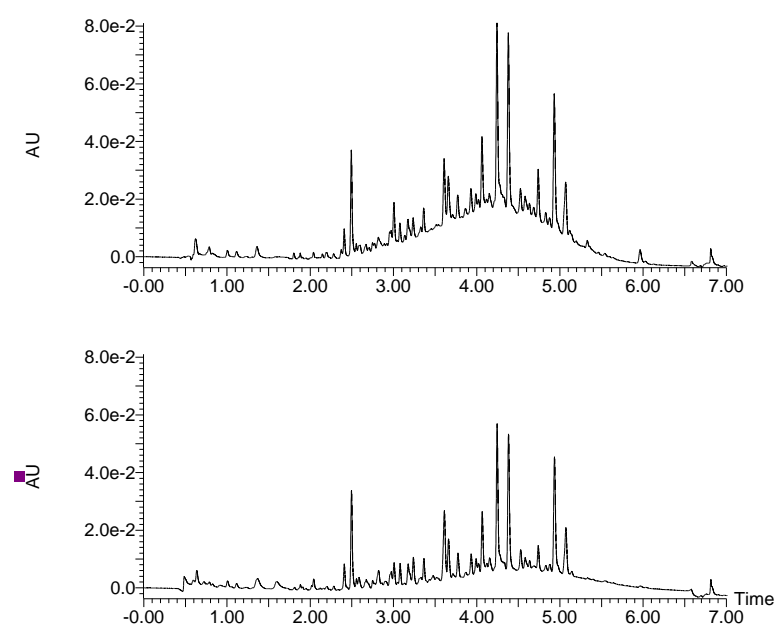
11. Begonia bowerae 'Nigra'
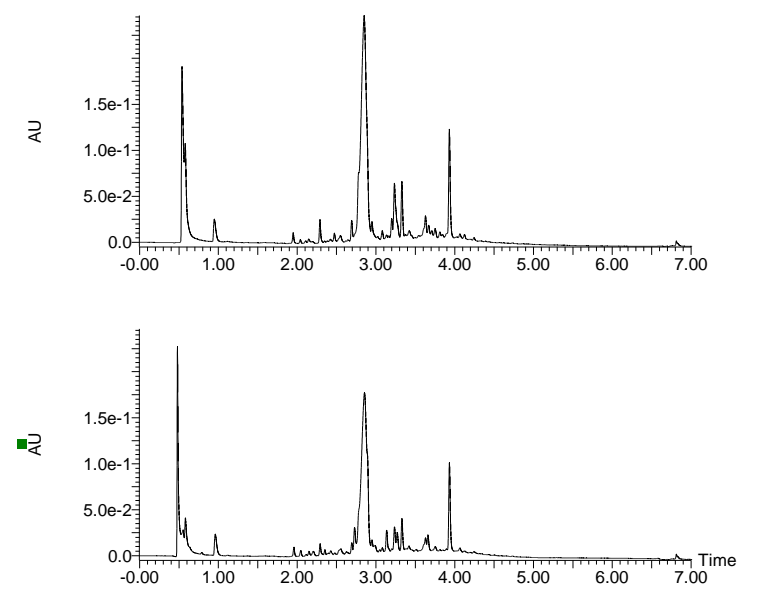

13. Cephalotaxus harringtonia subsp. drupacea
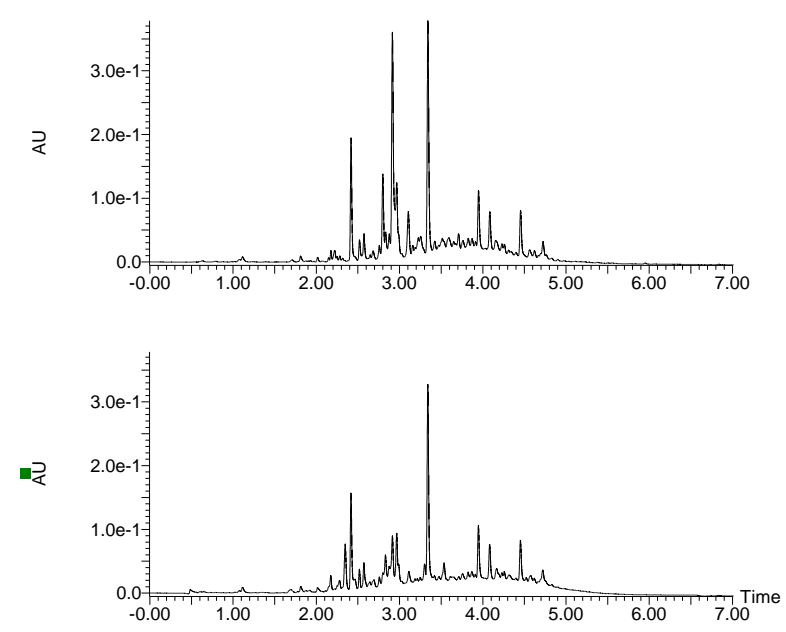

15. Combretum bracteosum
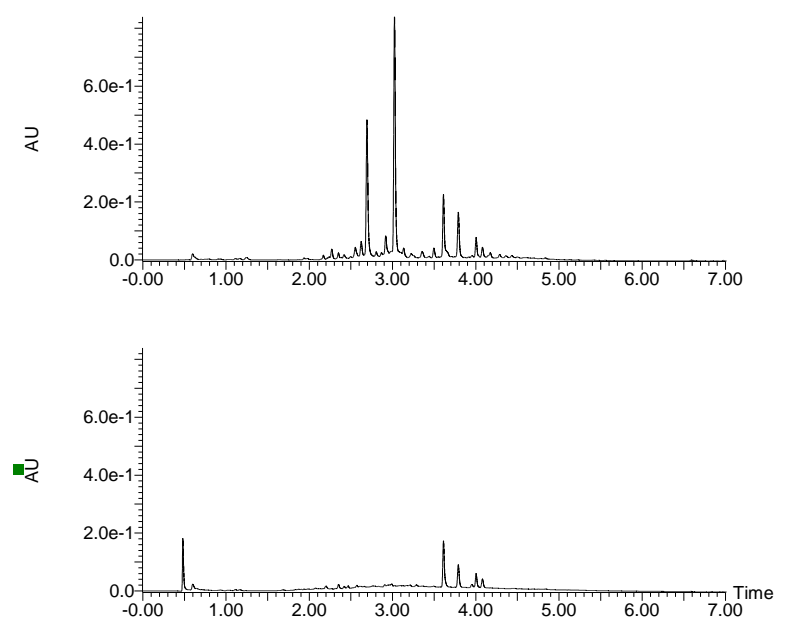

12. Allocasuarina campestris
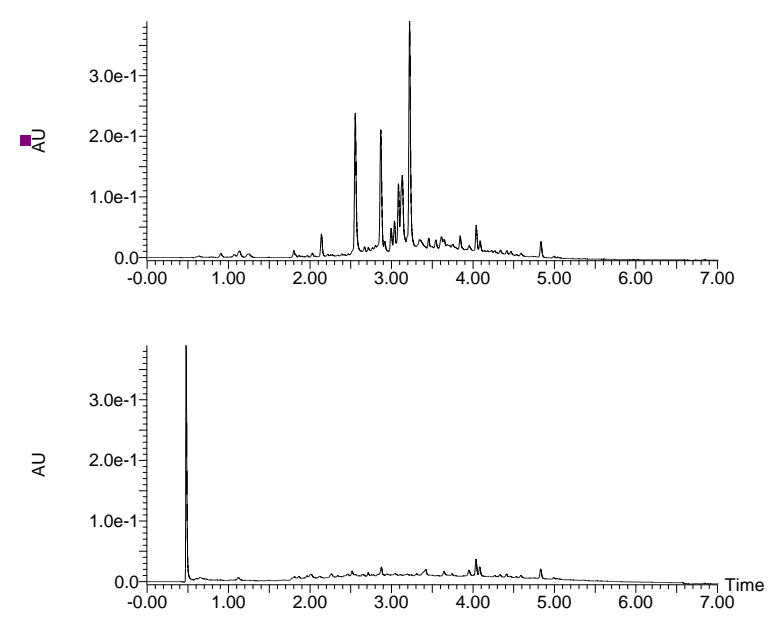

14. Callisia gentlei var. elegans
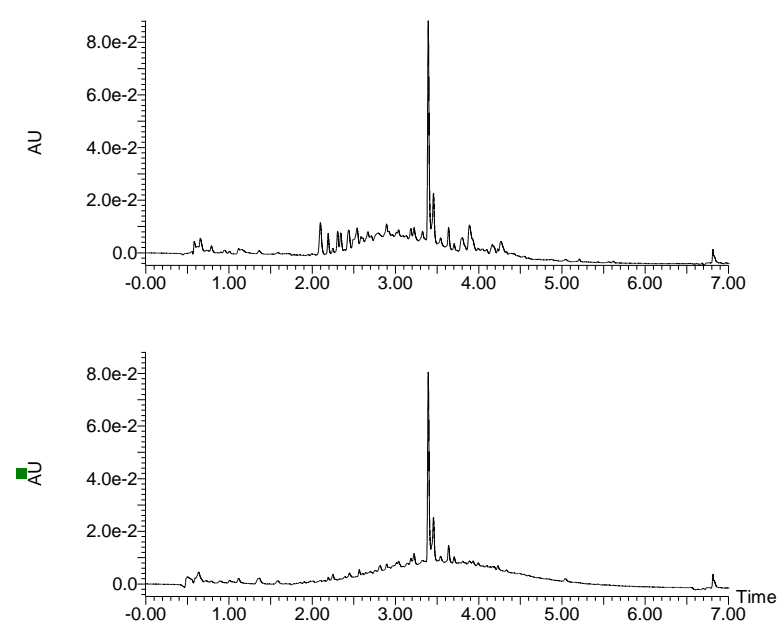

16. Combretum indicum
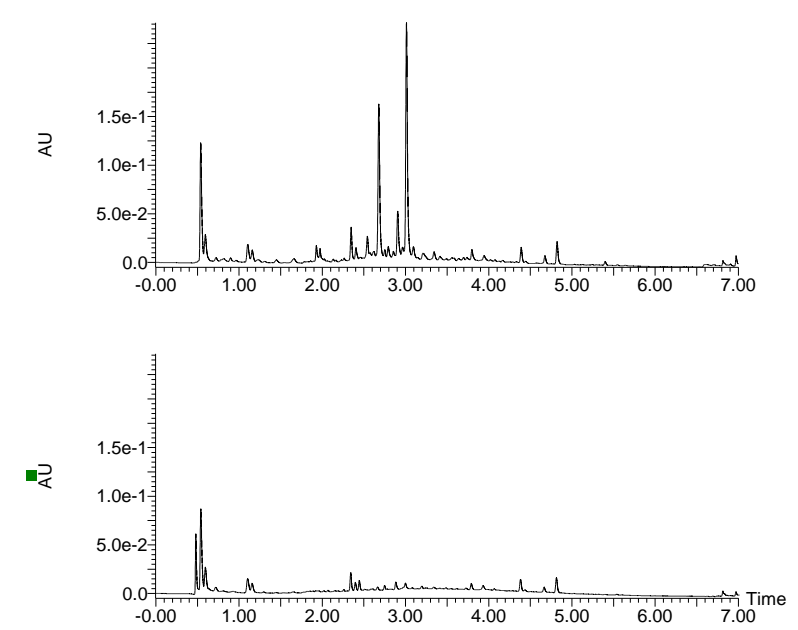
17. Aeonium arboreum
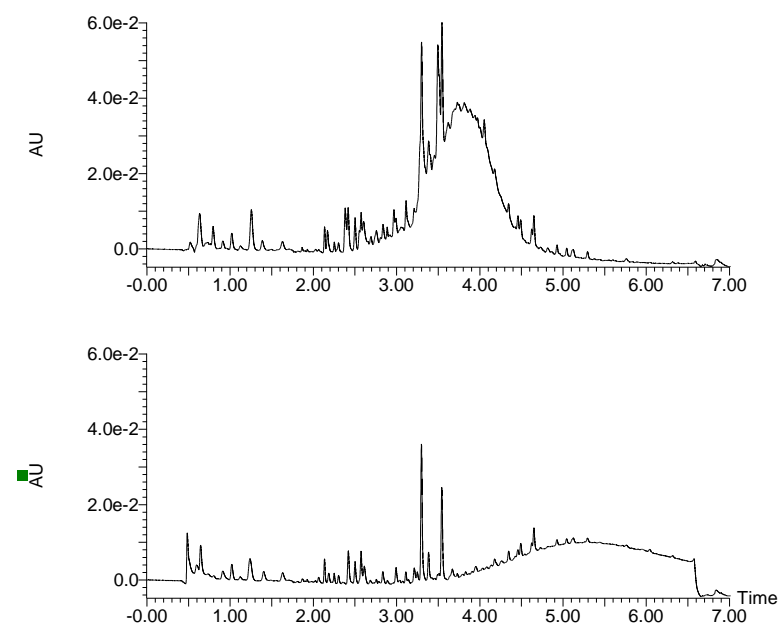

19. Echeveria harmsii
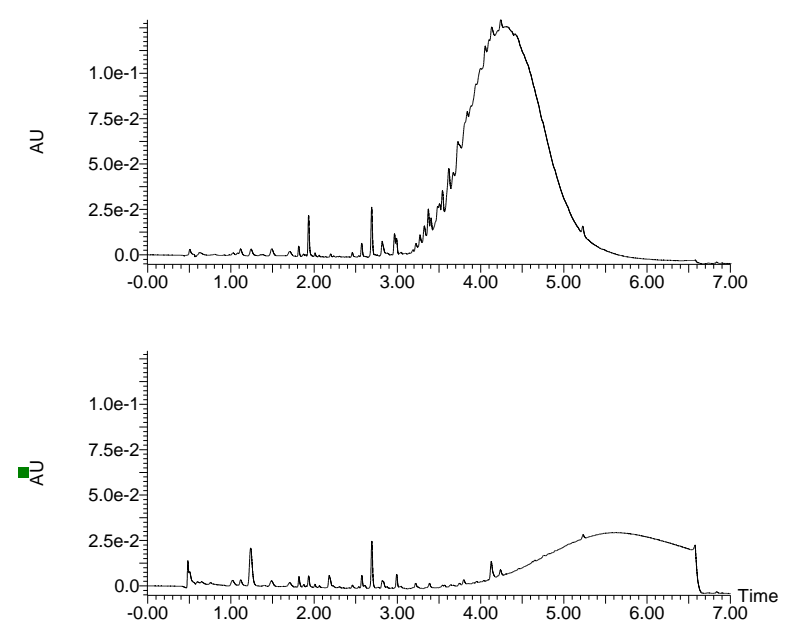

21. Pachyphytum hookeri
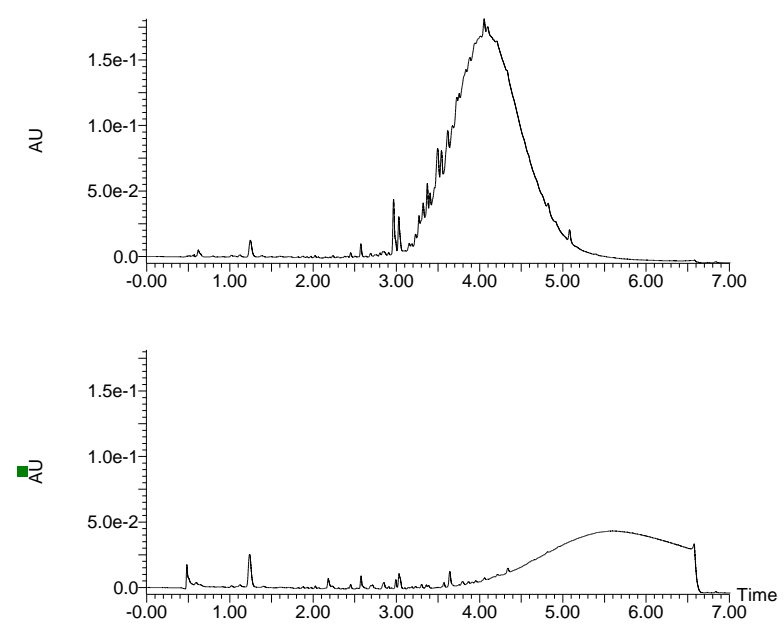

18. Crassula ovata
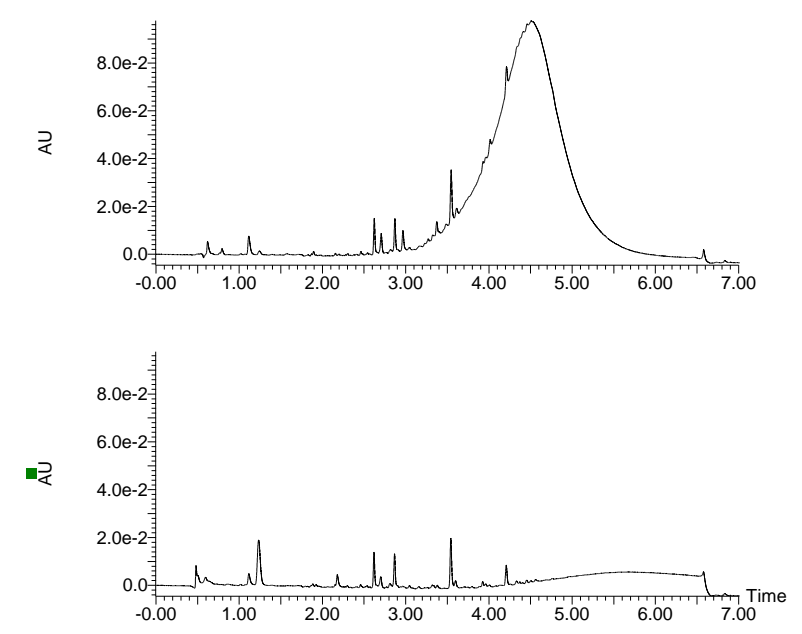

20. Kalanchö̈ manginii
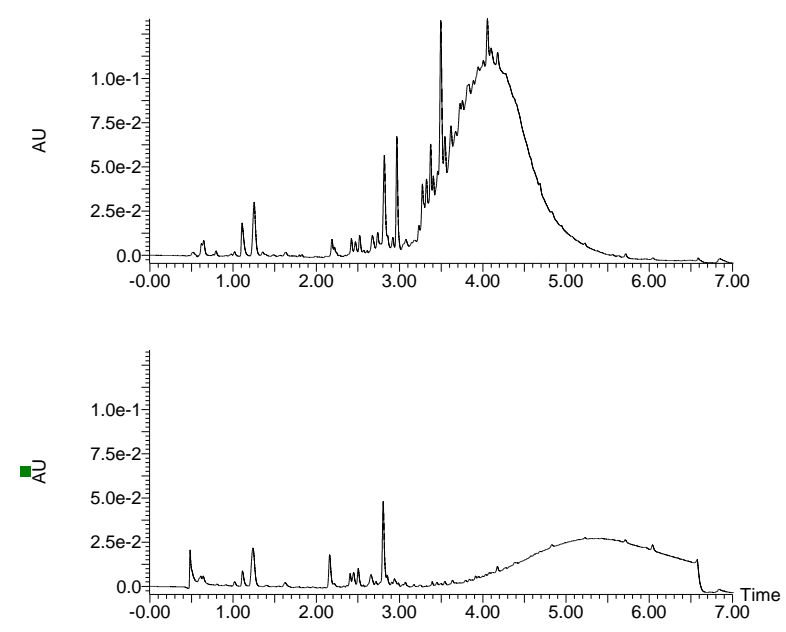

22. Sedum rubrotinctum
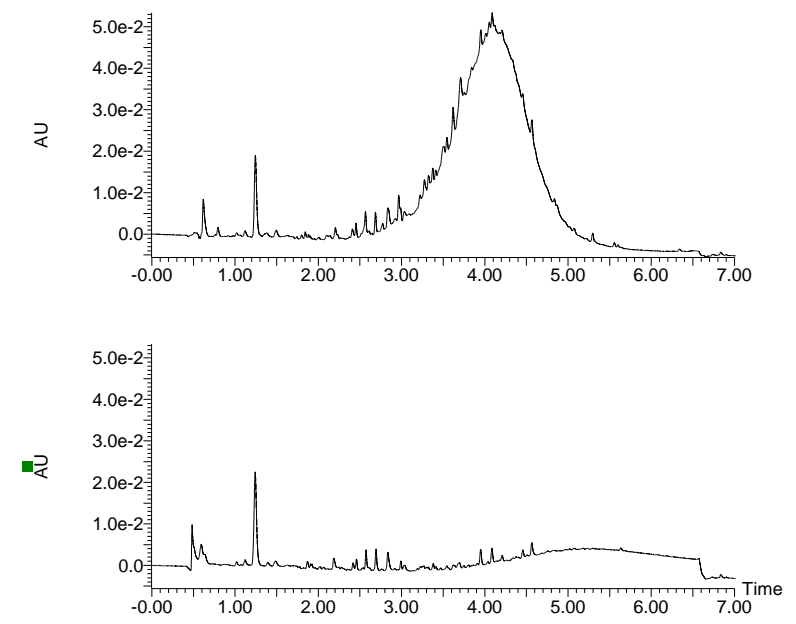
23. Villadia batesii
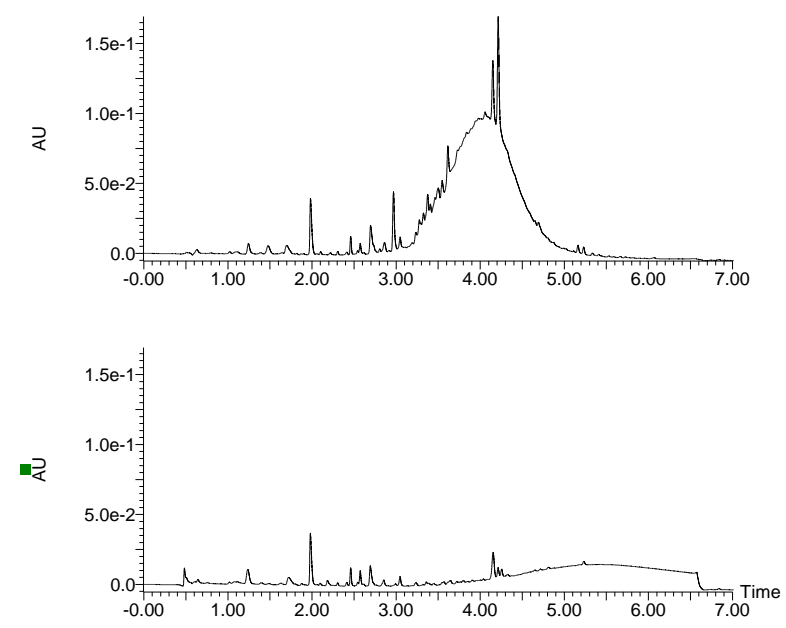

25. Cupressus bakeri
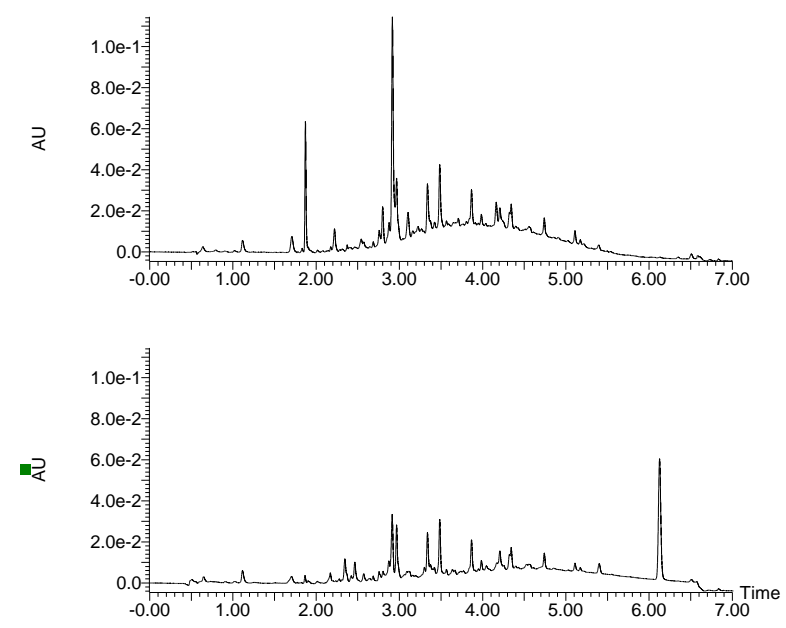

27. Tetraclinis articulata
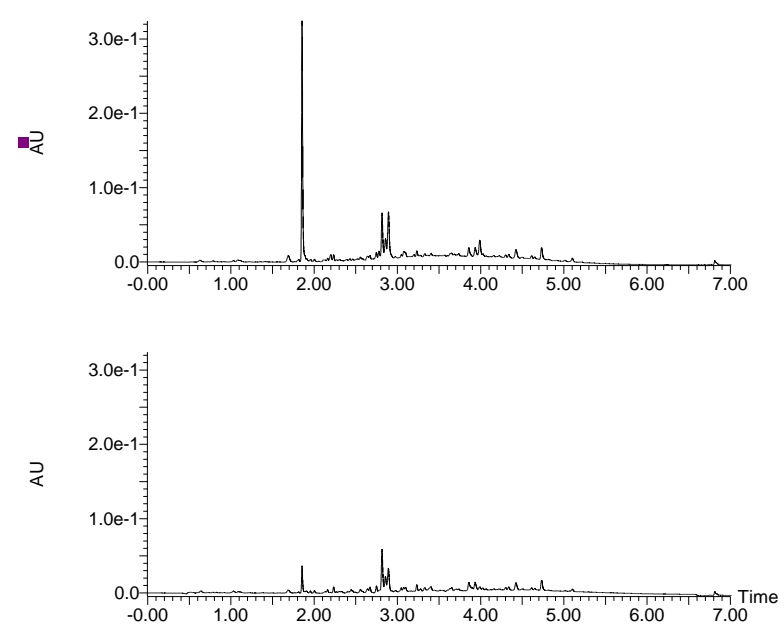

\section{Cunninghamia lanceolata}
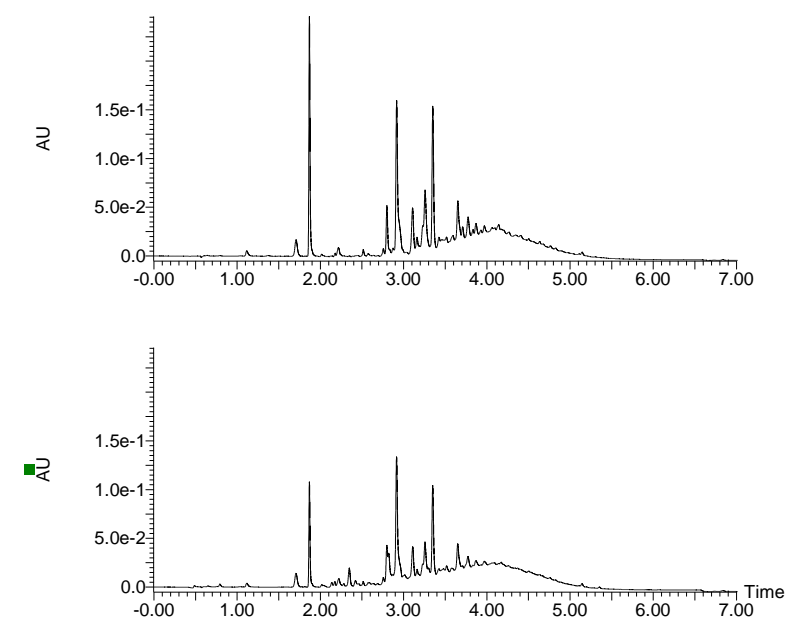

26. Sequoia sempervirens
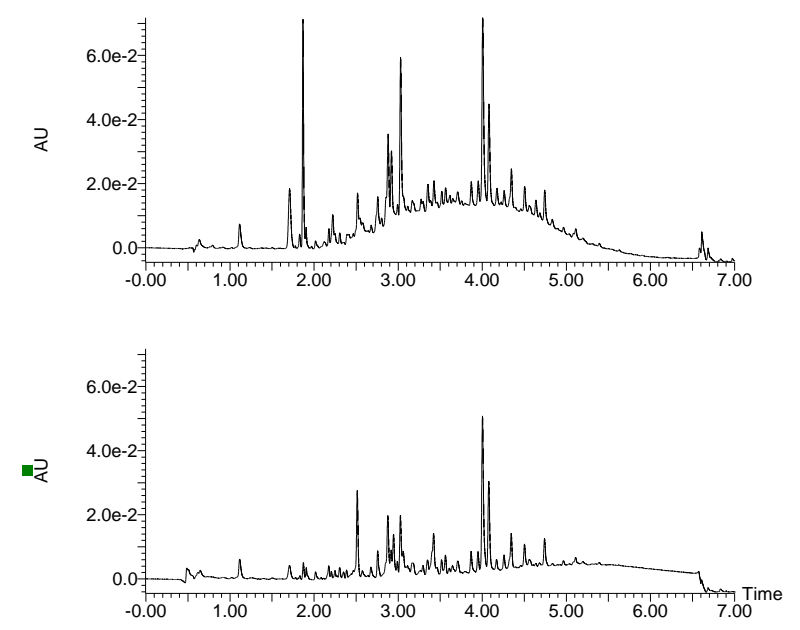

28. Cyperus owanii
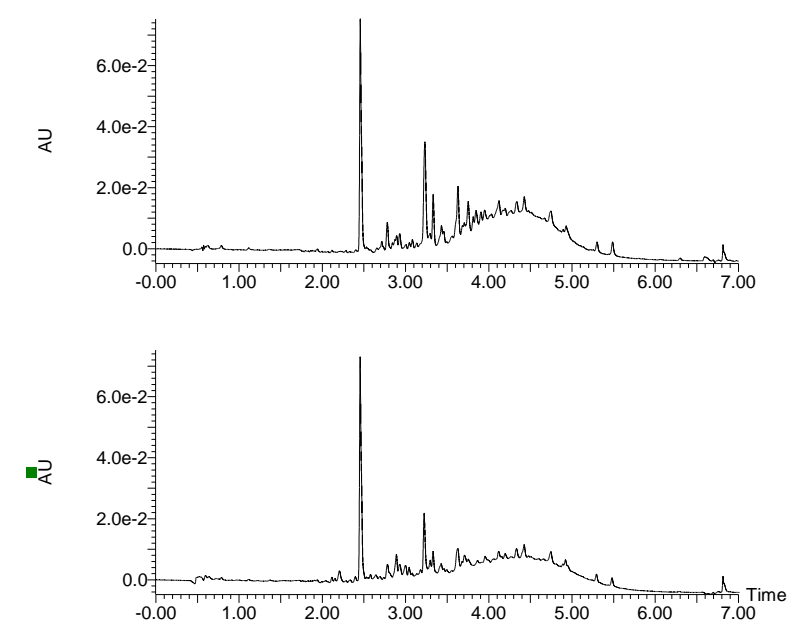
29. Cyperus owanii
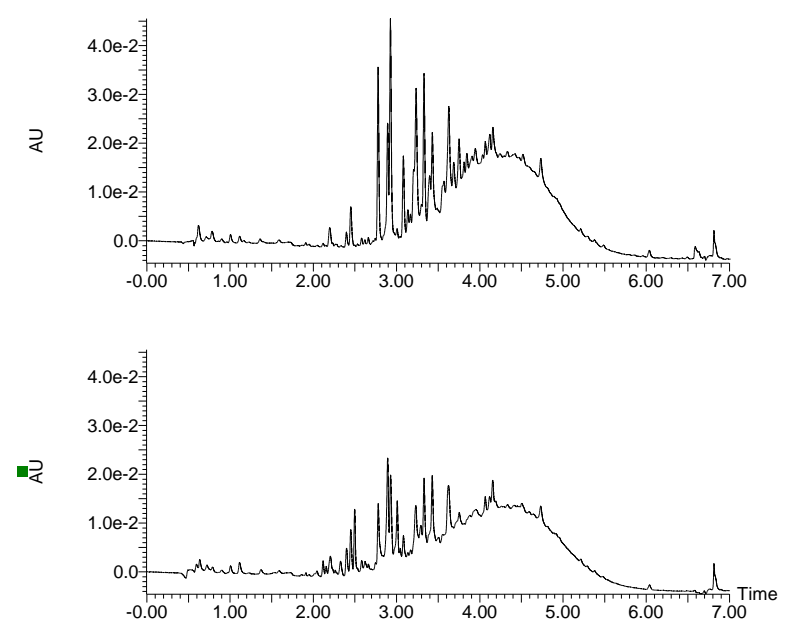

\section{Dicksonia squarrosa}
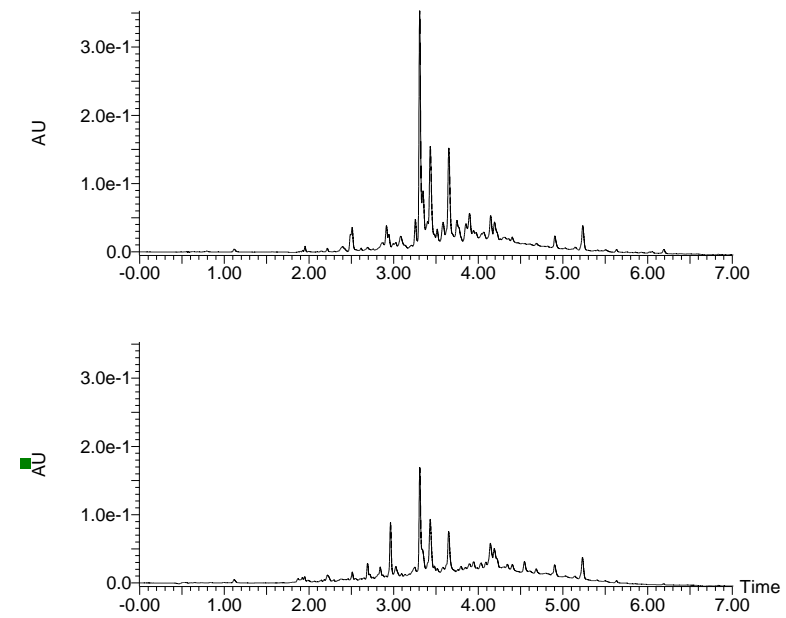

\section{Polystichum proliferum}
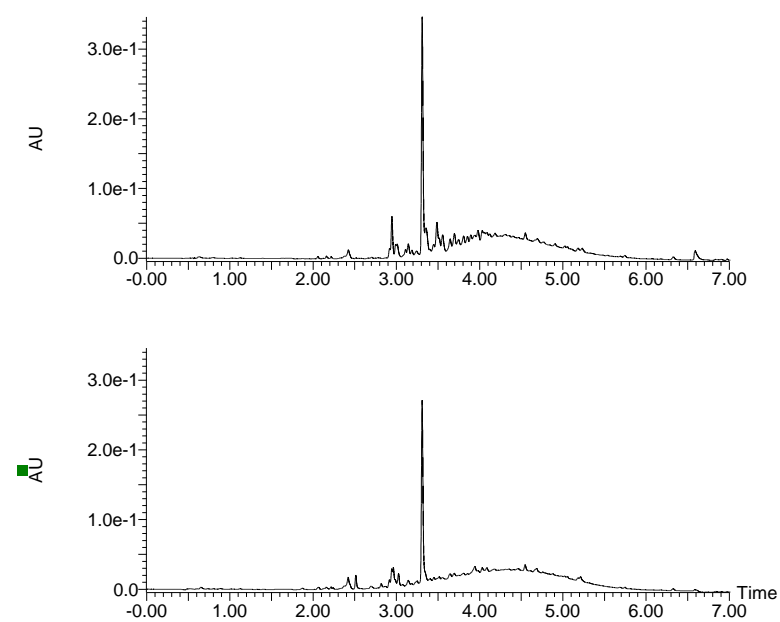

30. Davallia pyxidata
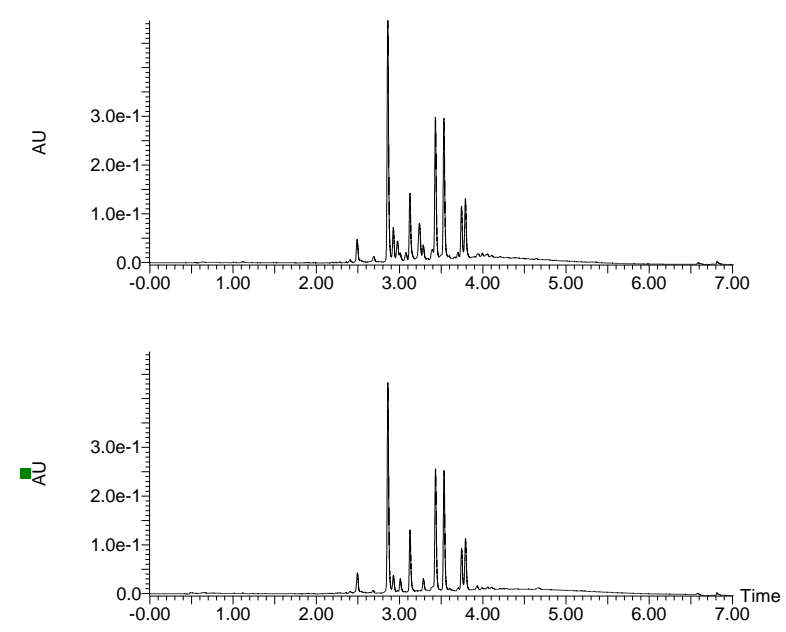

32. Cyrtomium falcatum
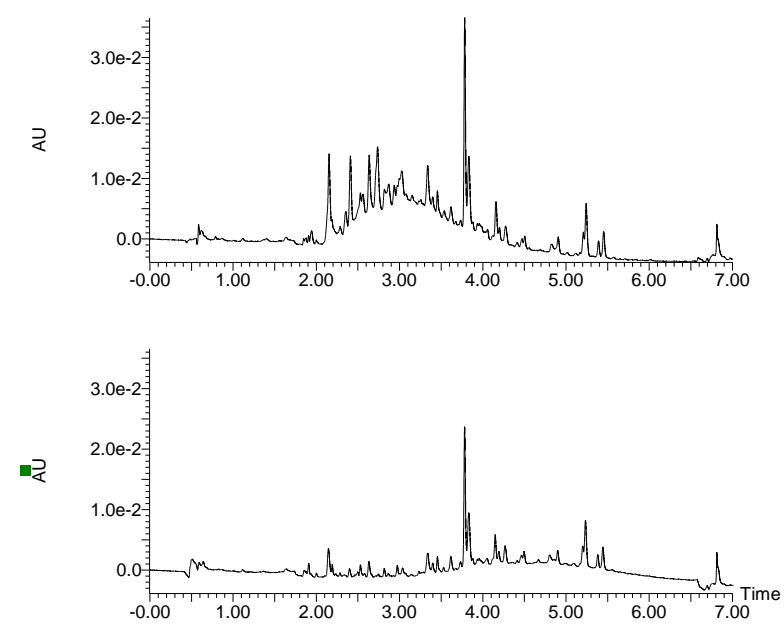

\section{Diospyros mespiliformis}
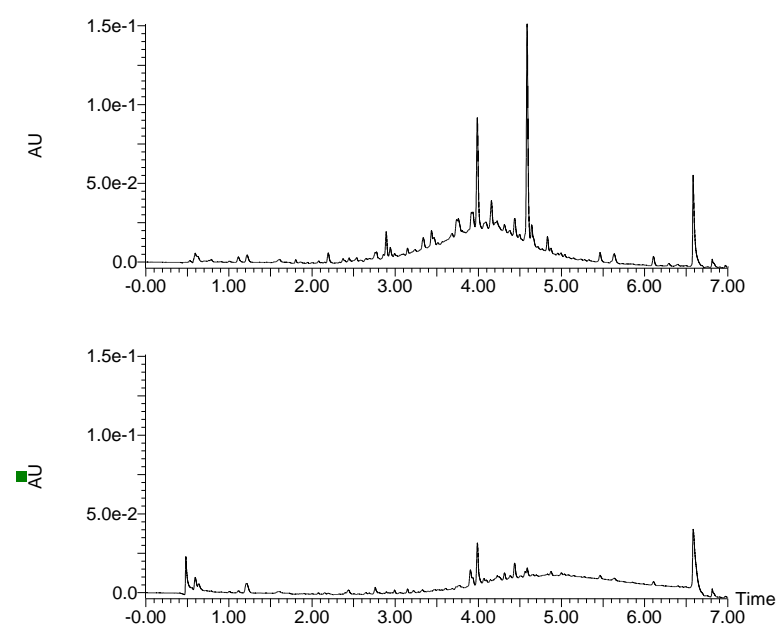


\section{Rhododendron hemitrichotum}
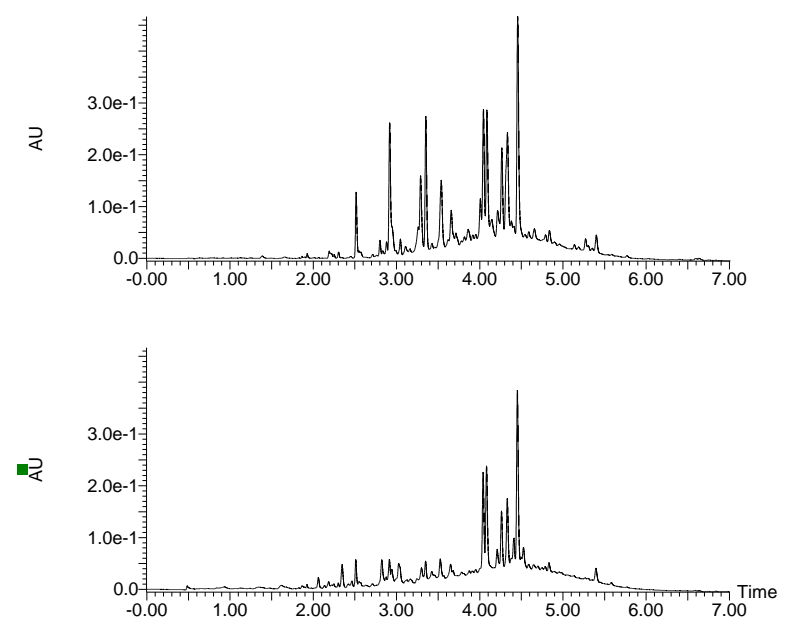

37. Euphorbia characias (leaves)
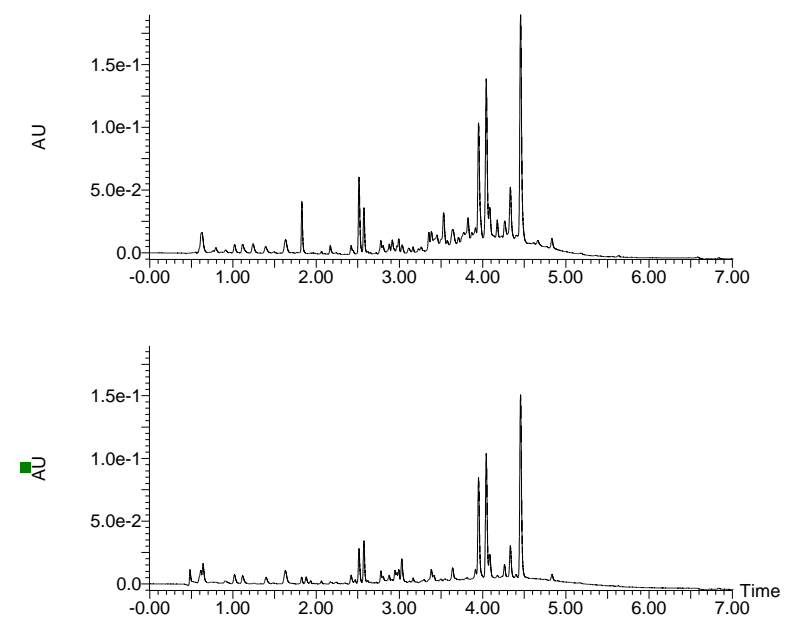

39. Acacia karroo
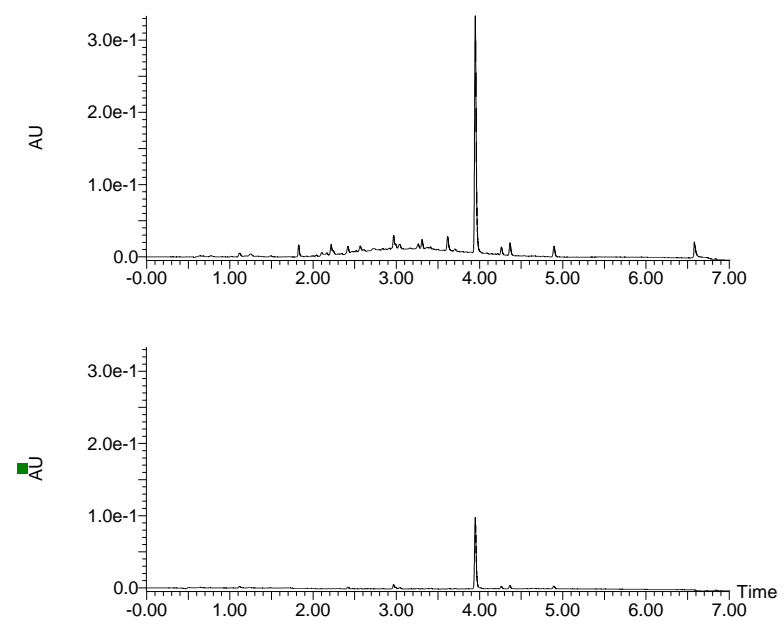

36. Rhododendron hemitrichotum
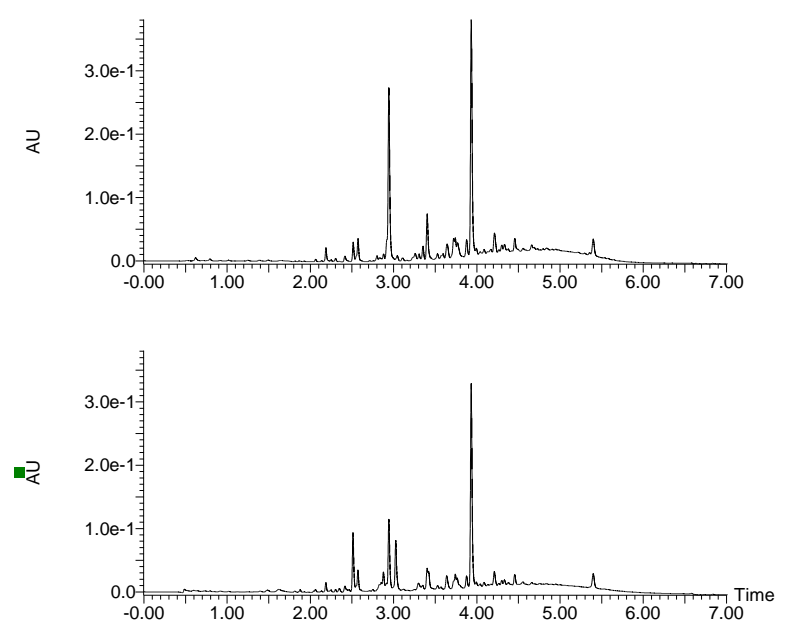

\section{Euphorbia characias (flowers)}
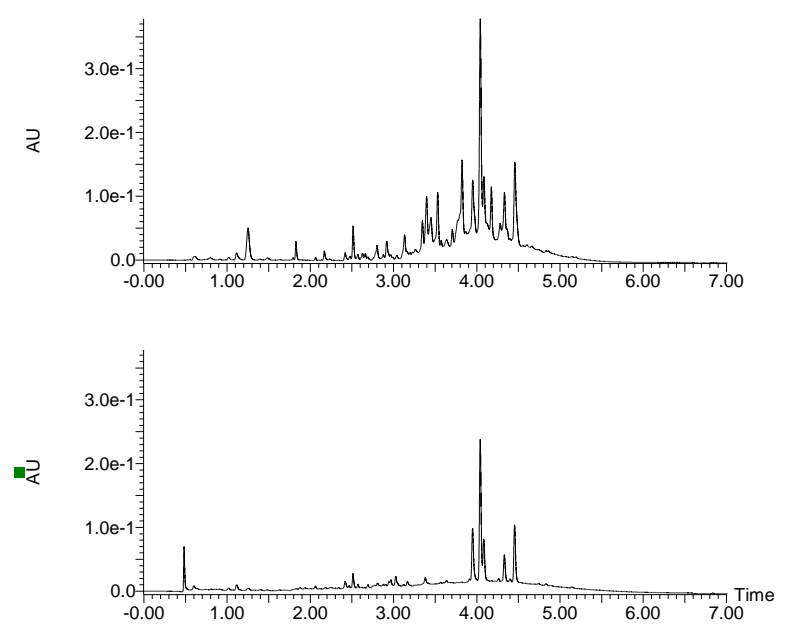

40. Acacia melanoxylon
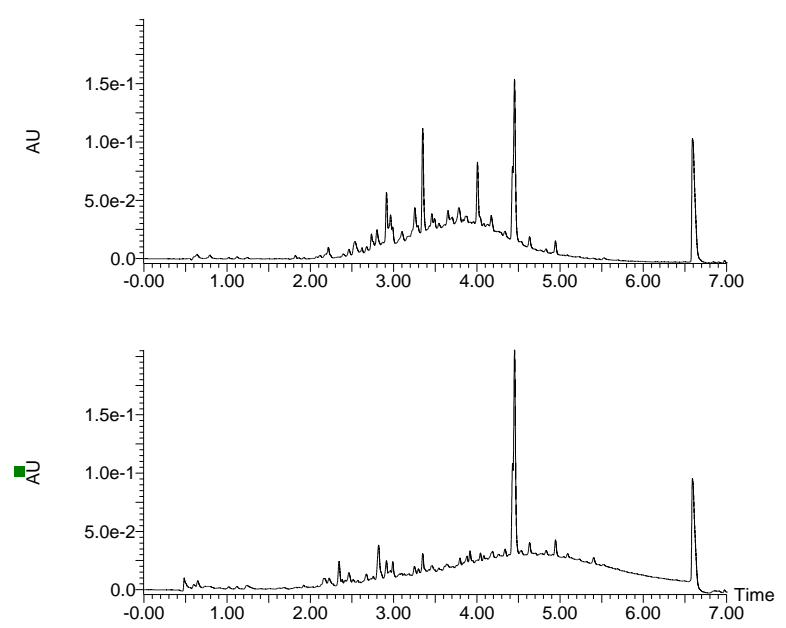
41. Acacia victoriae
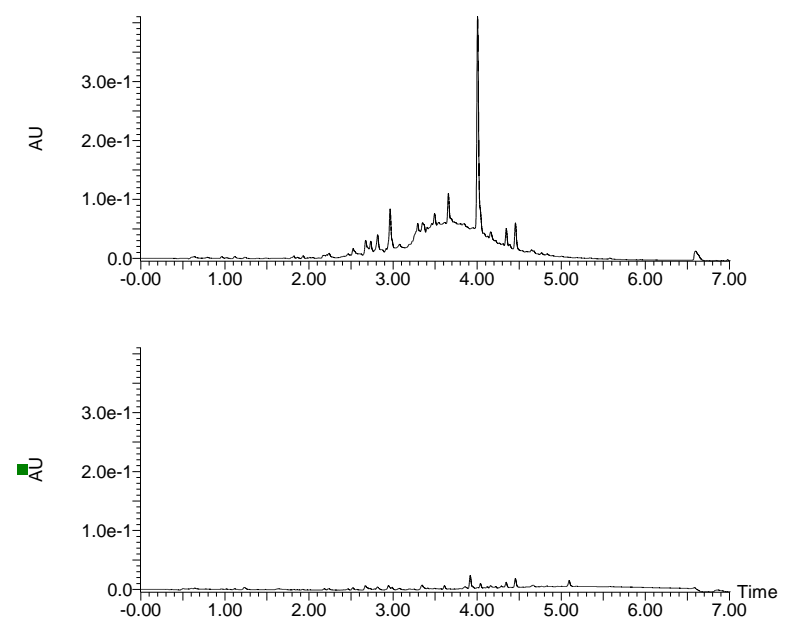

43. Calliandra haematocephala
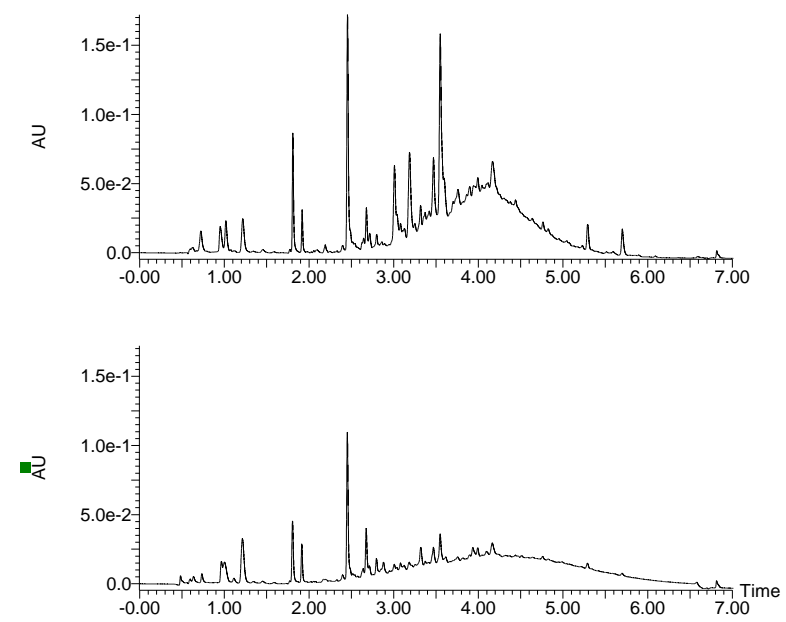

45. Mimosa polycarpa
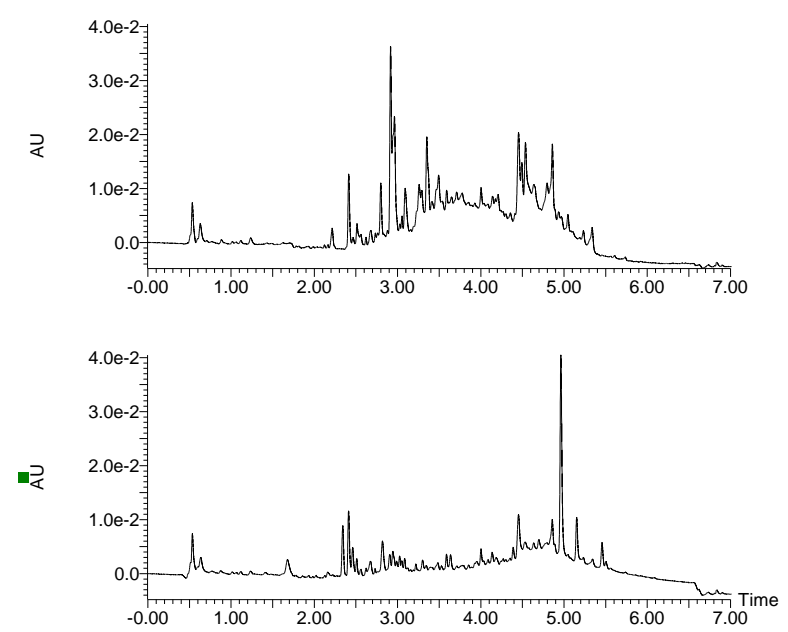

42. Bauhinia variegata
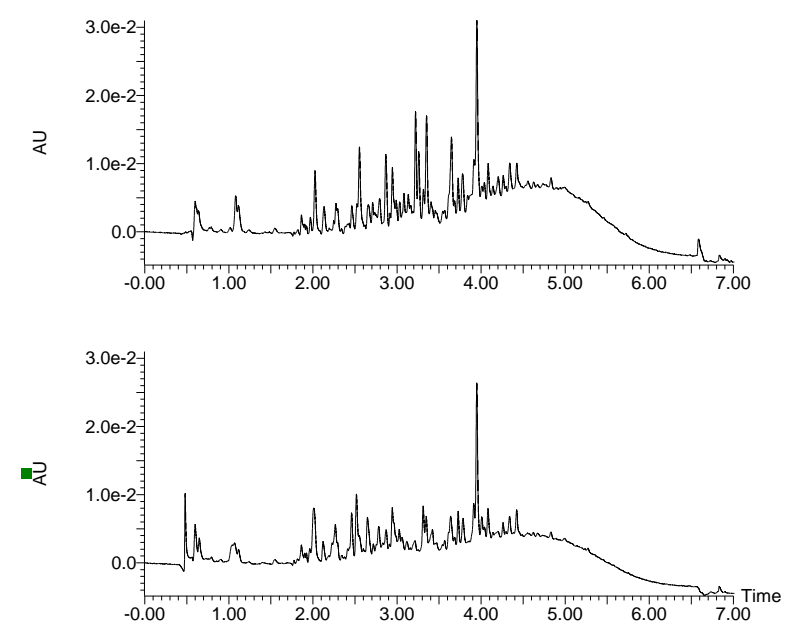

44. Ceratonia siliqua
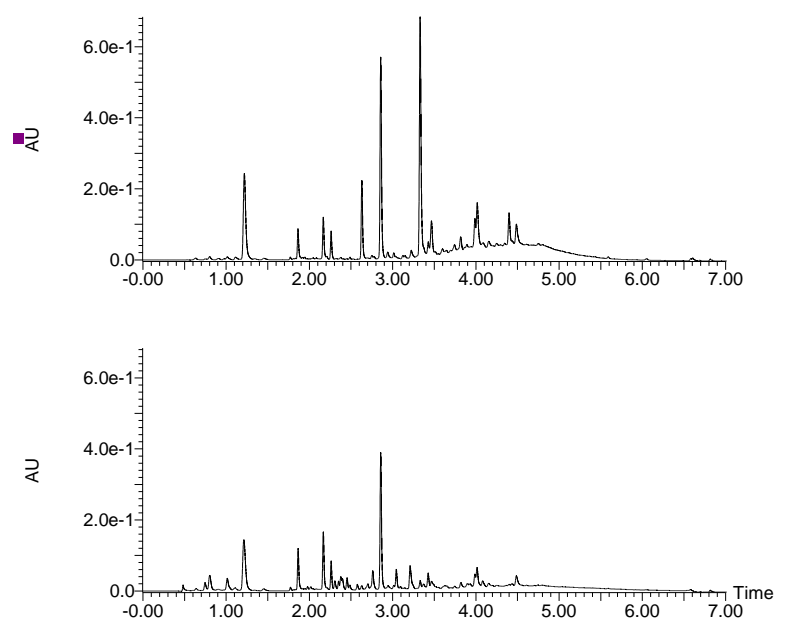

46. Newtonia buchananii
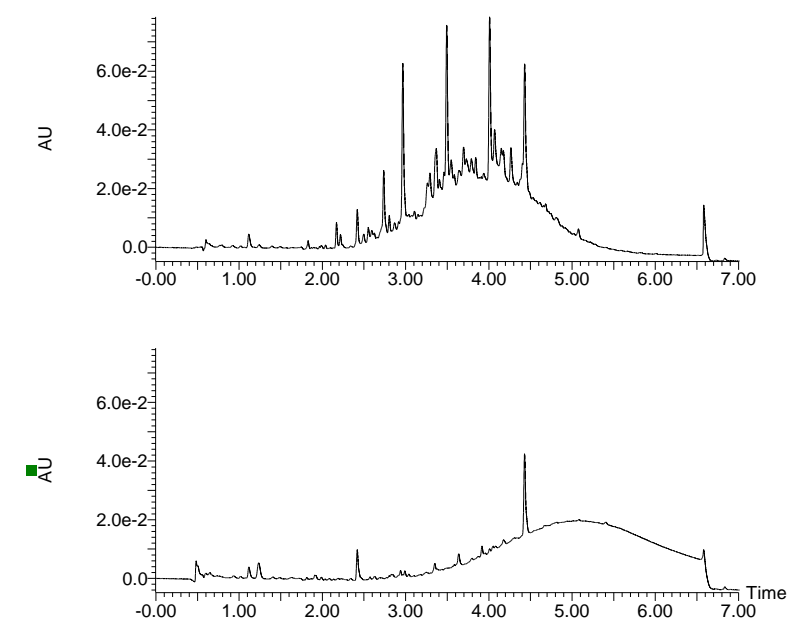
47. Quercus ilex
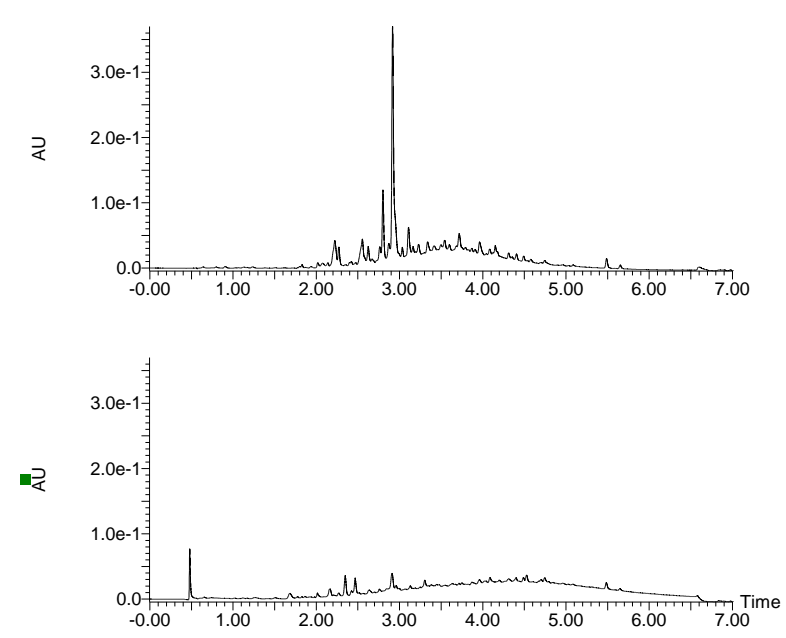

\section{Apollonias barbujana}
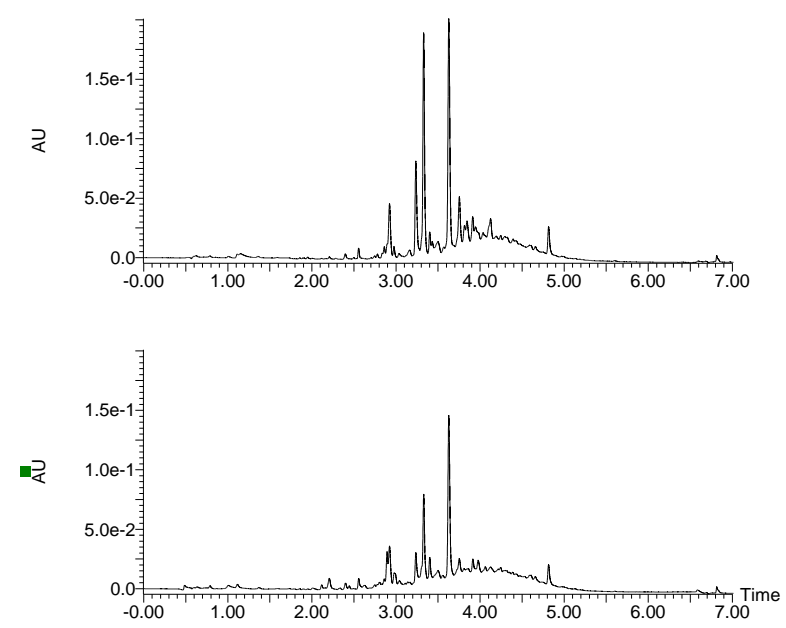

\section{Heritiera solomonensis}
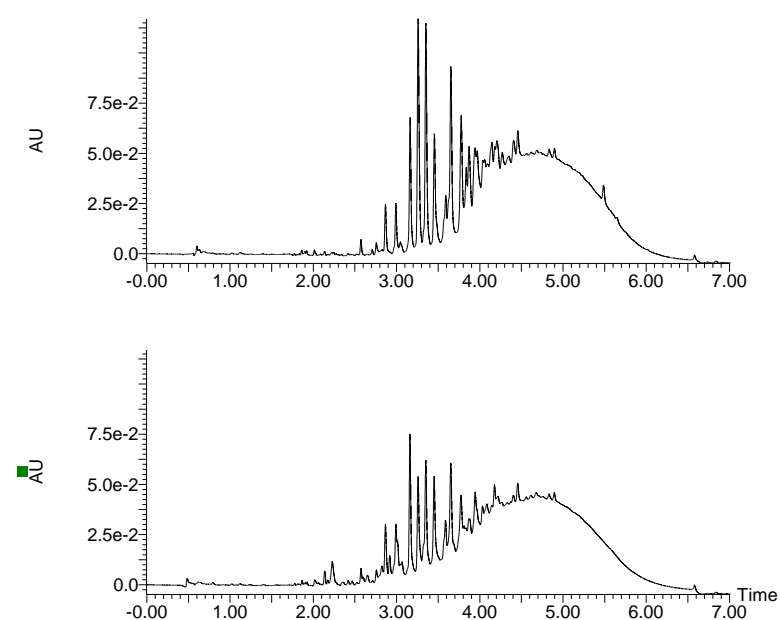

48. Pelargonium odoratissimum
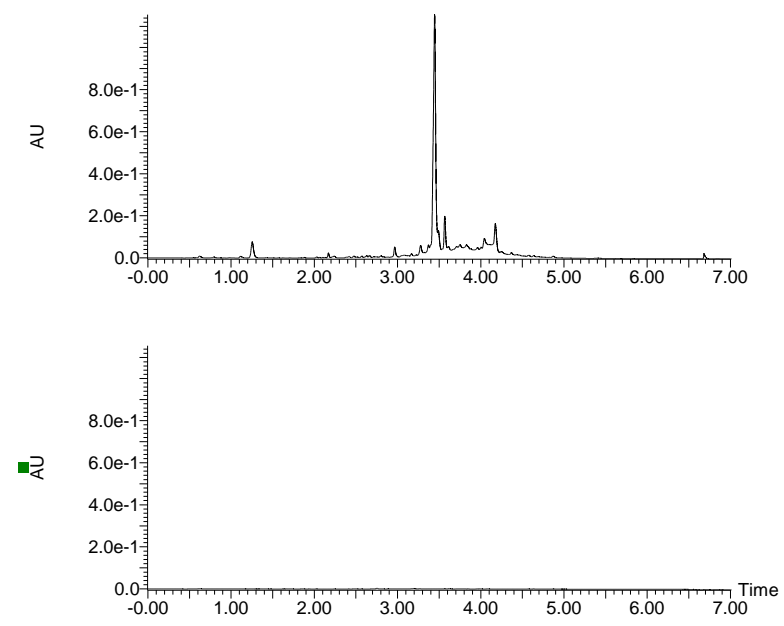

\section{Laurus nobilis}
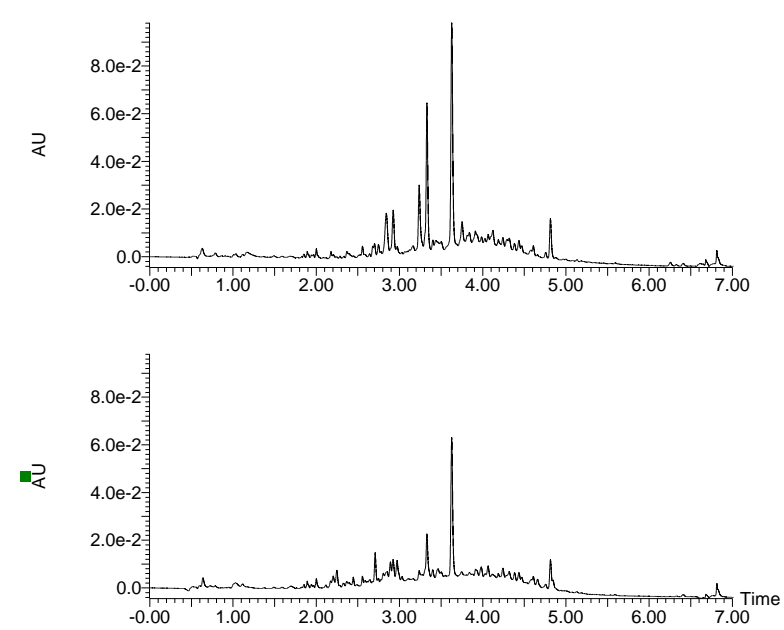

52. Pavonia cauliflora
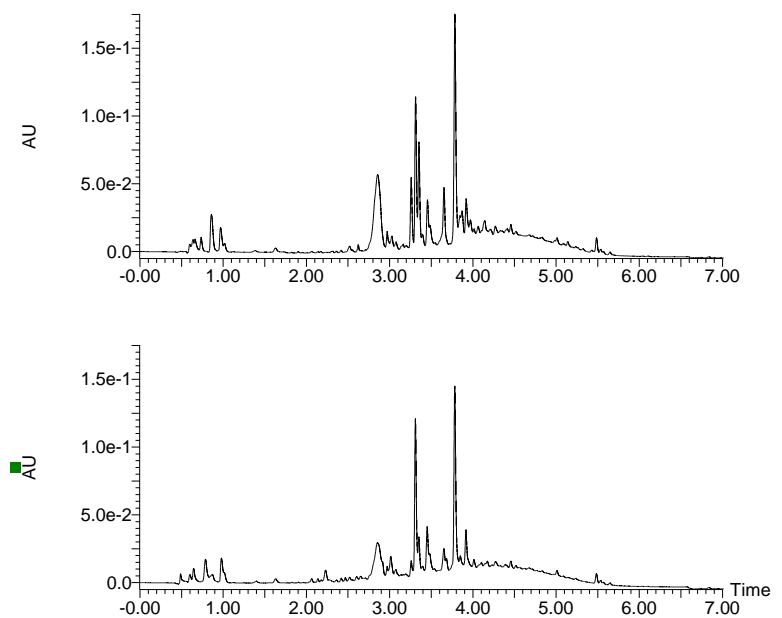
53. Marcgravia umbellata
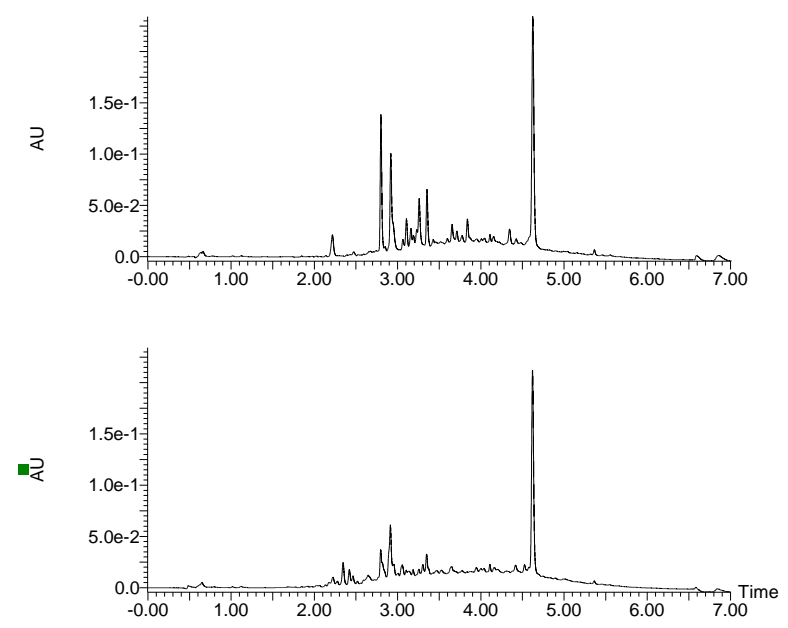

55. Artocarpus sp.
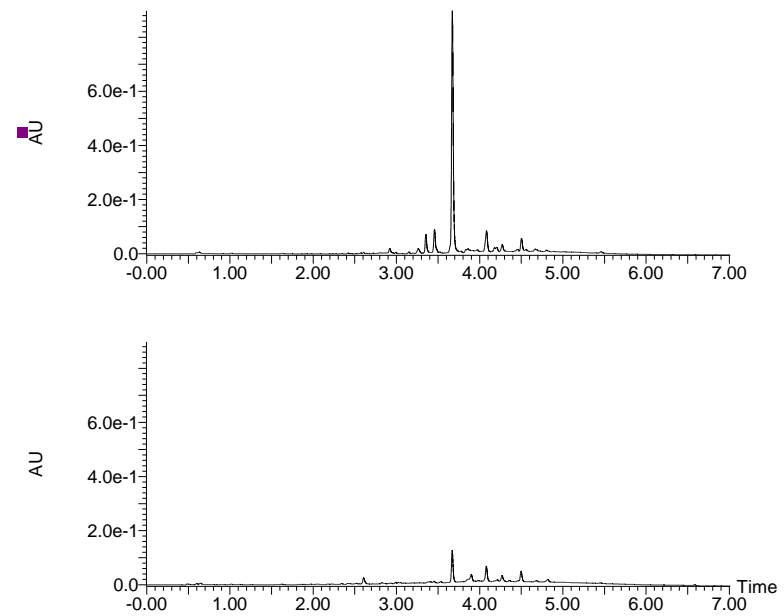

57. Callistemon citrinus
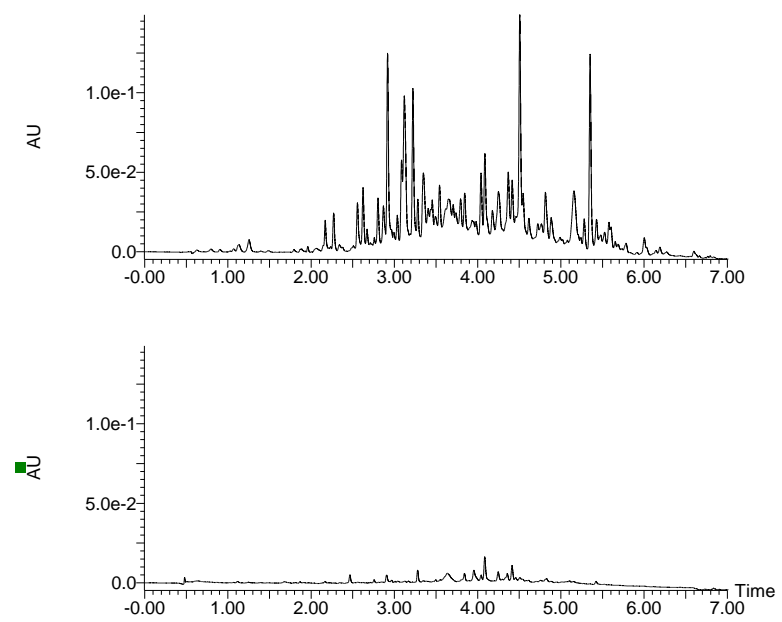

54. Medinilla magnifica
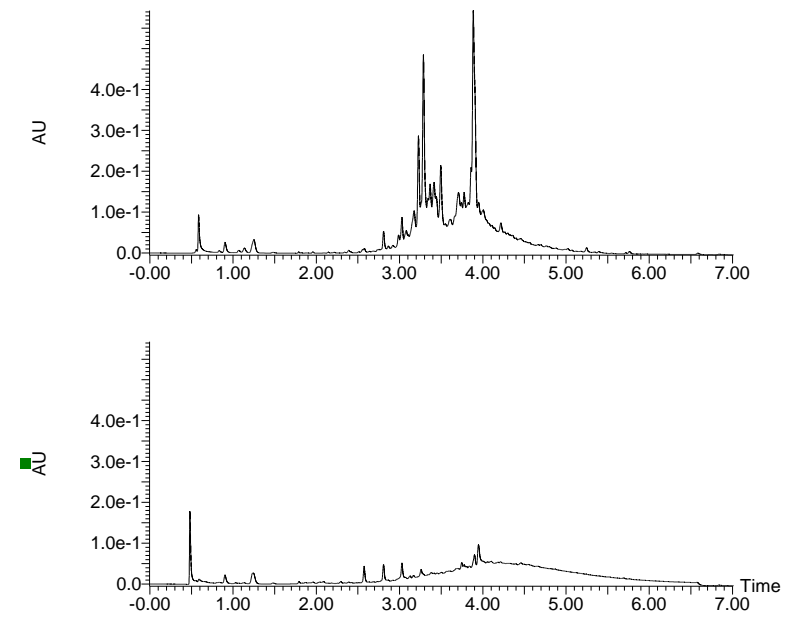

56. Acca sellowiana
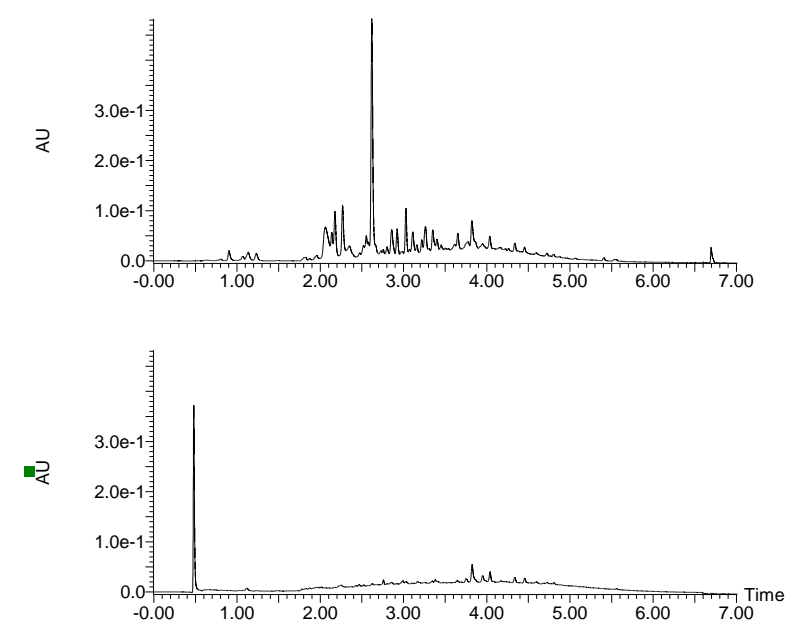

58. Melaleuca squarrosa
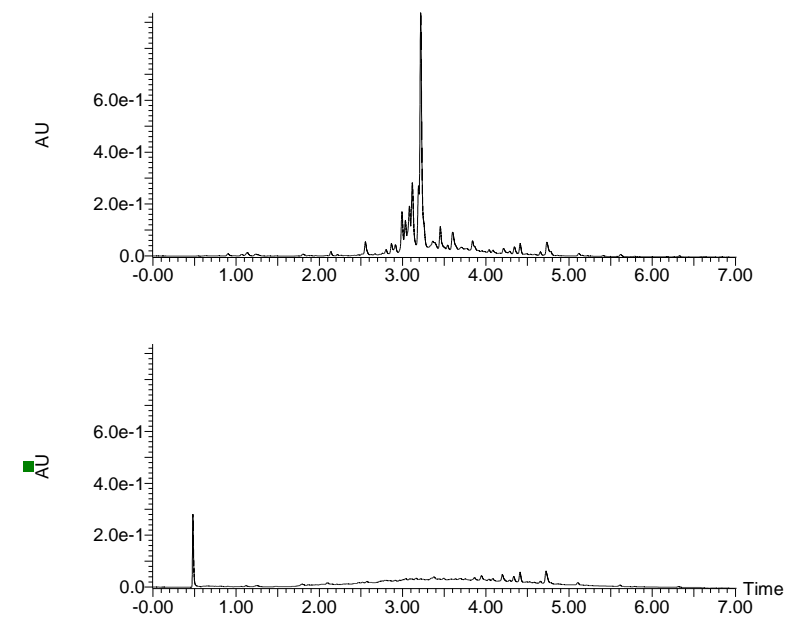
59. Myrtus communis
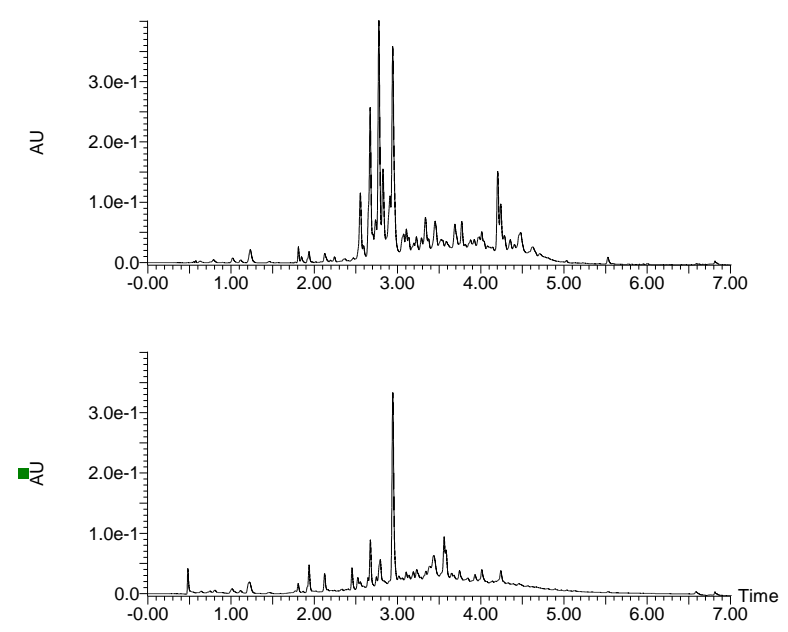

61. Psidium cattleianum
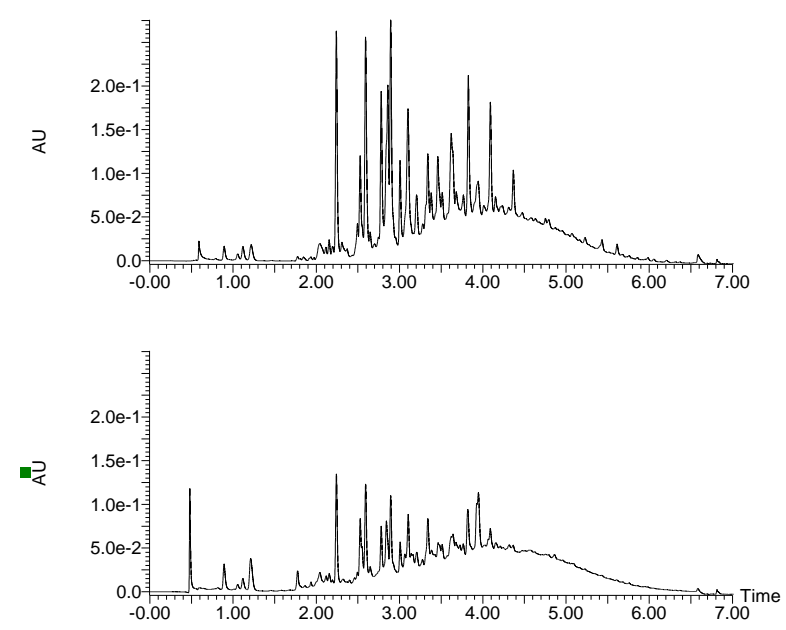

63. Nepenthes maxima
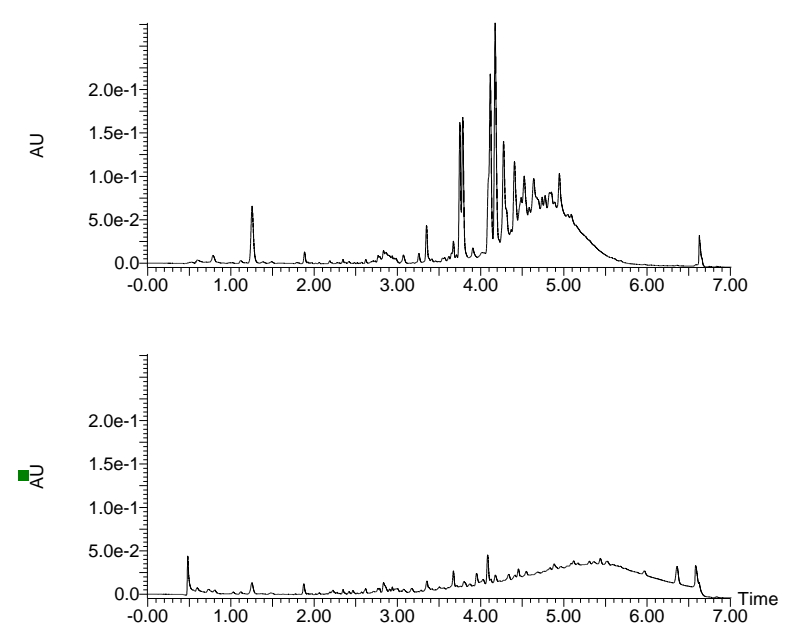

60. Psidium cattleianum
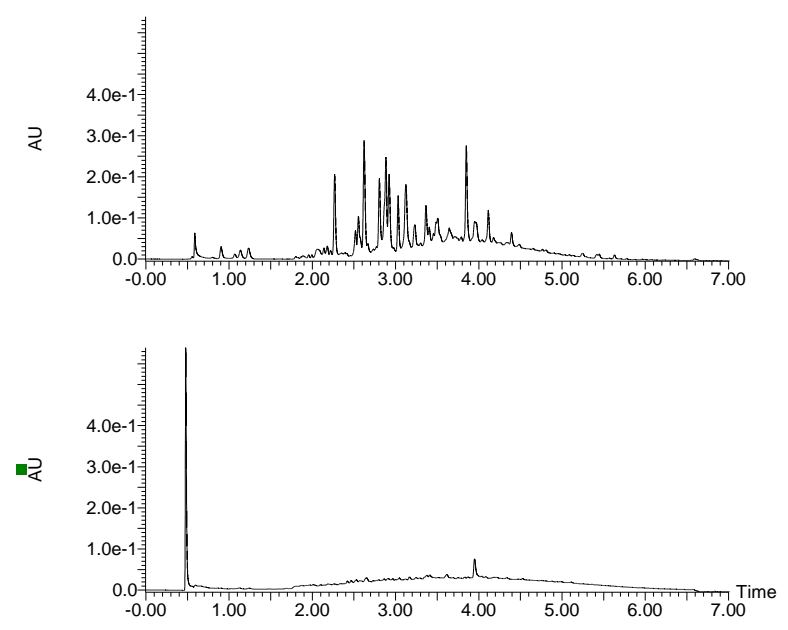

62. Nepenthes maxima
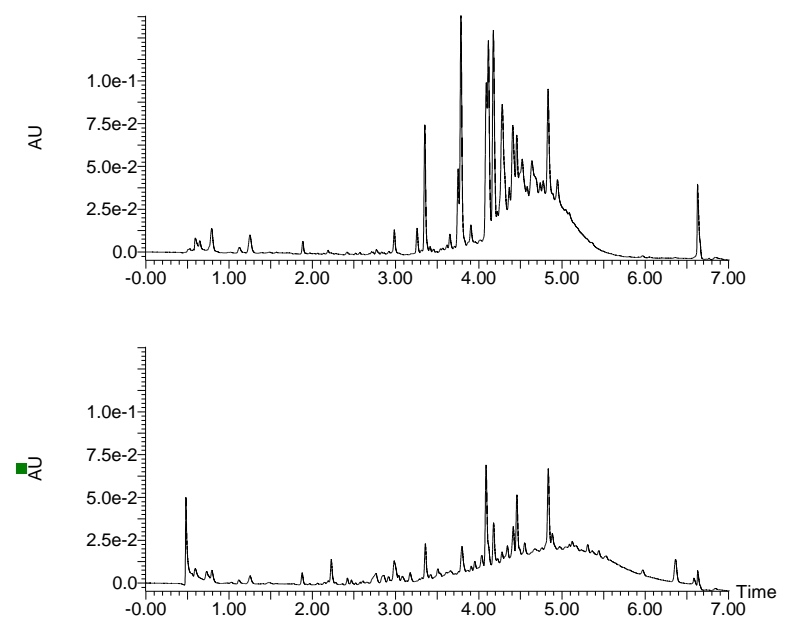

64. Biophytum sensitivum
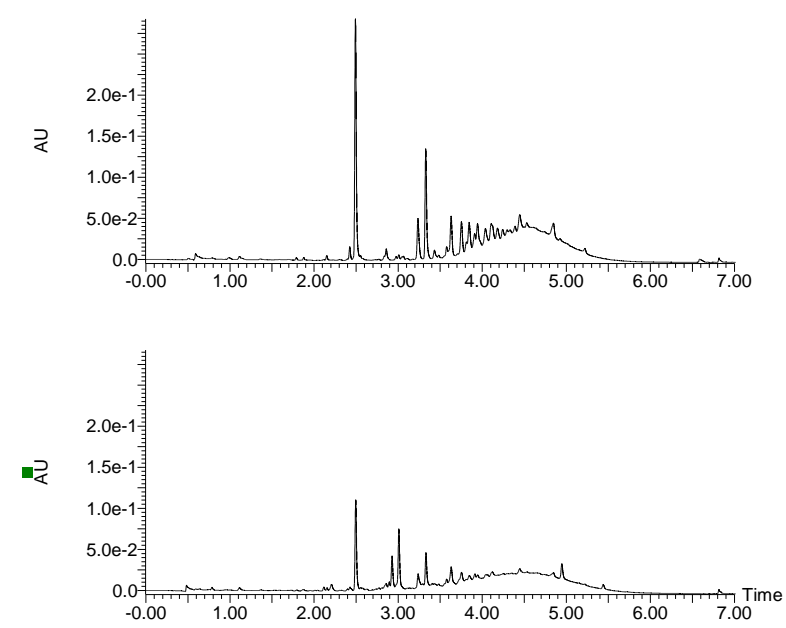
65. Phyllanthus juglandifolius/grandifolius
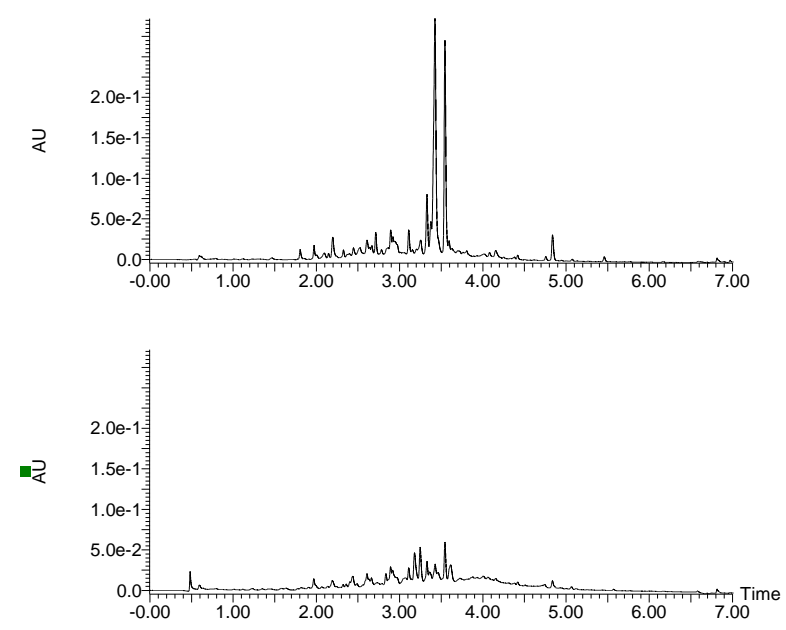

67. Coccoloba uvifera
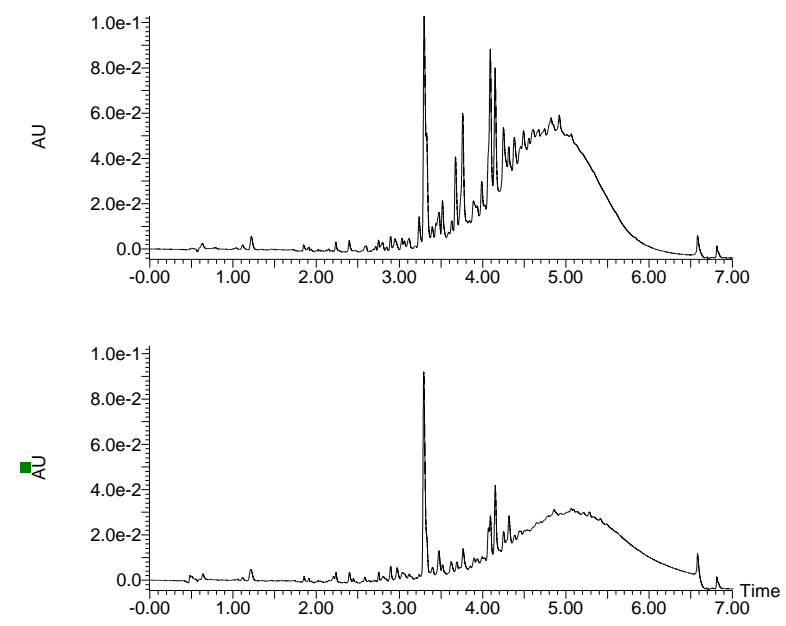

69. Microgramma vacciniifolia
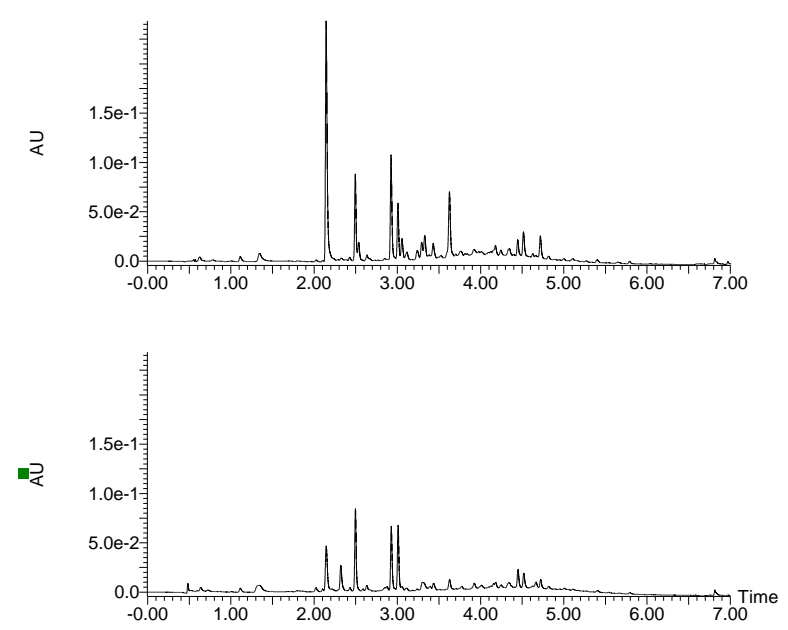

66. Podocarpus macrophyllus
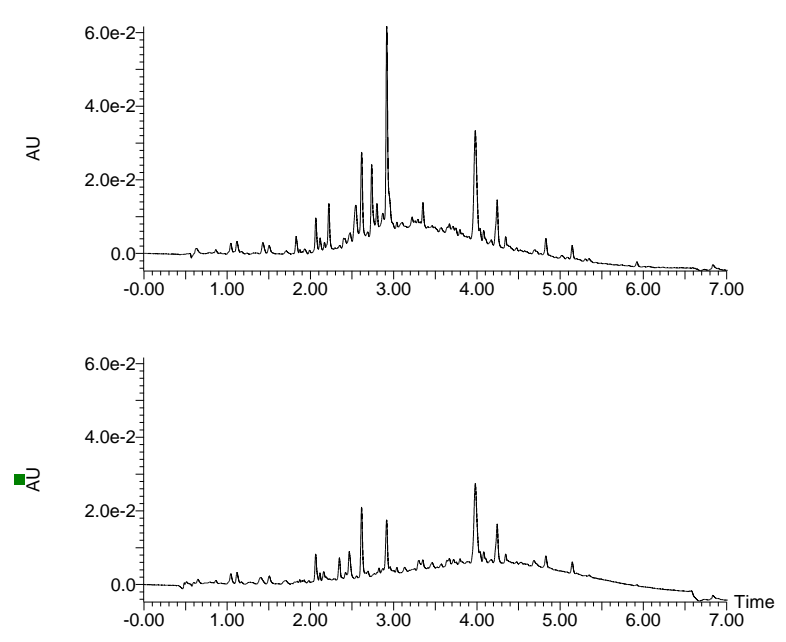

68. Microgramma mauritiana
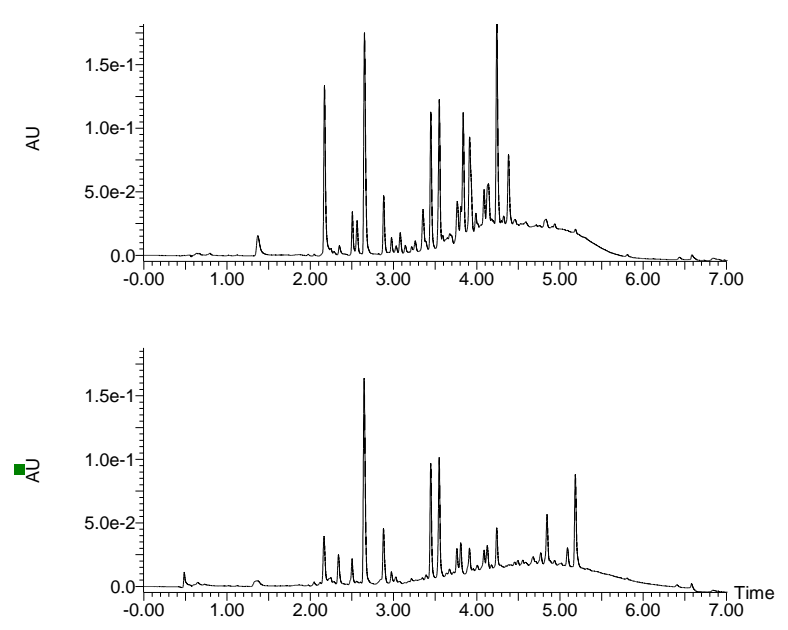

70. Ruprechtia salicifolia
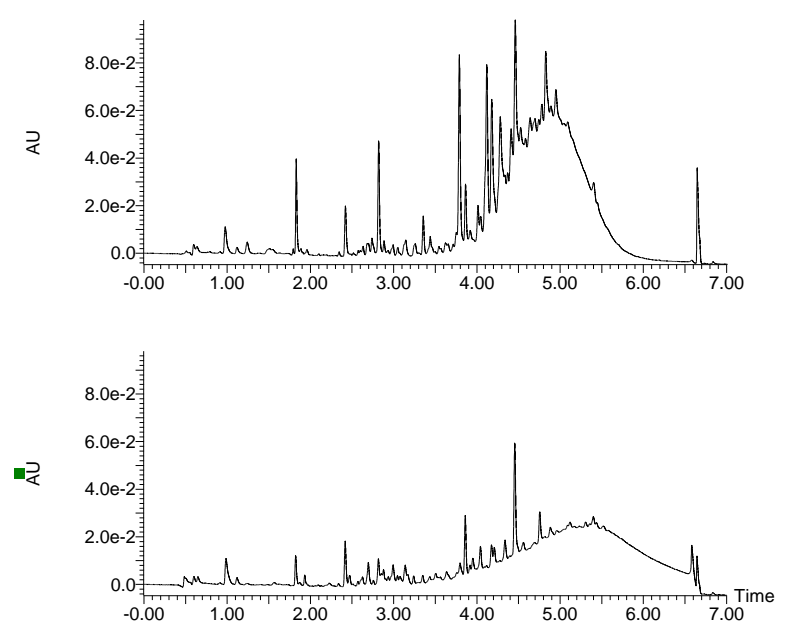
71. Portulaca alata
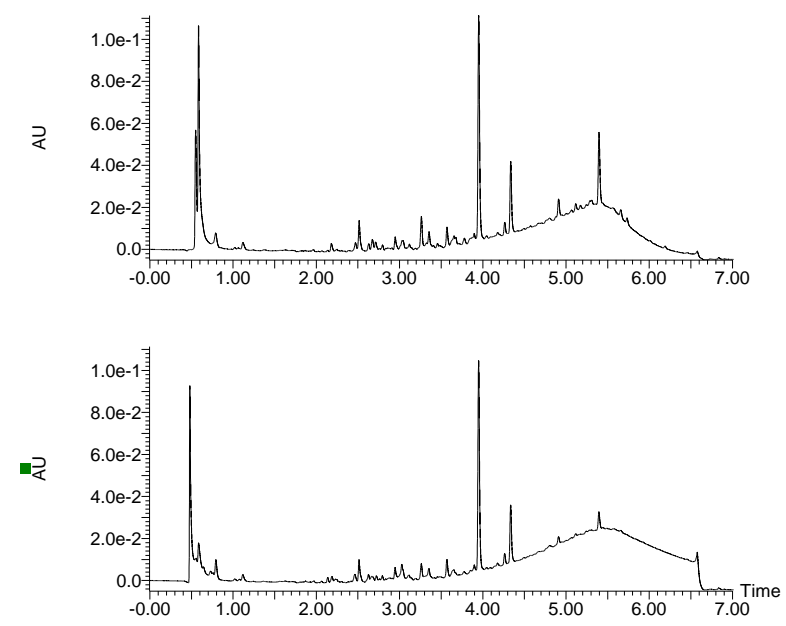

73. Ardisia crenata
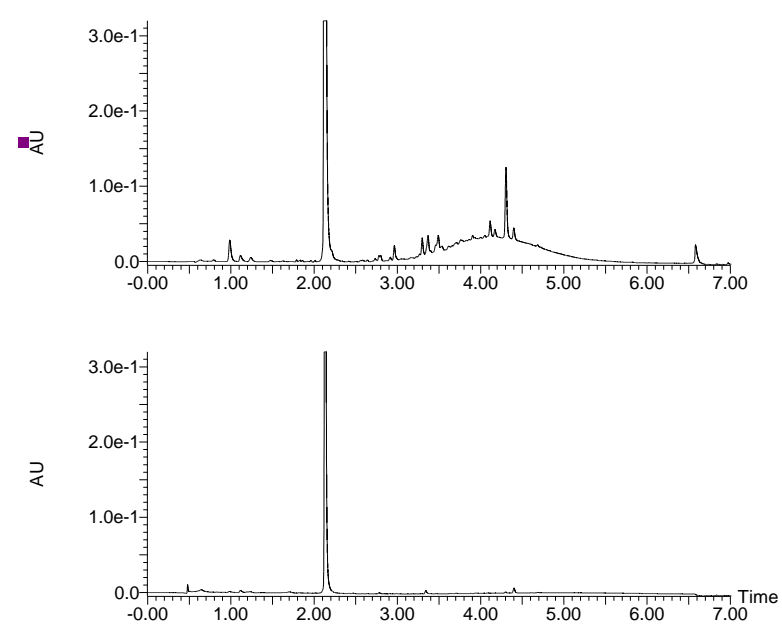

75. Pellaea ovata (pieces)
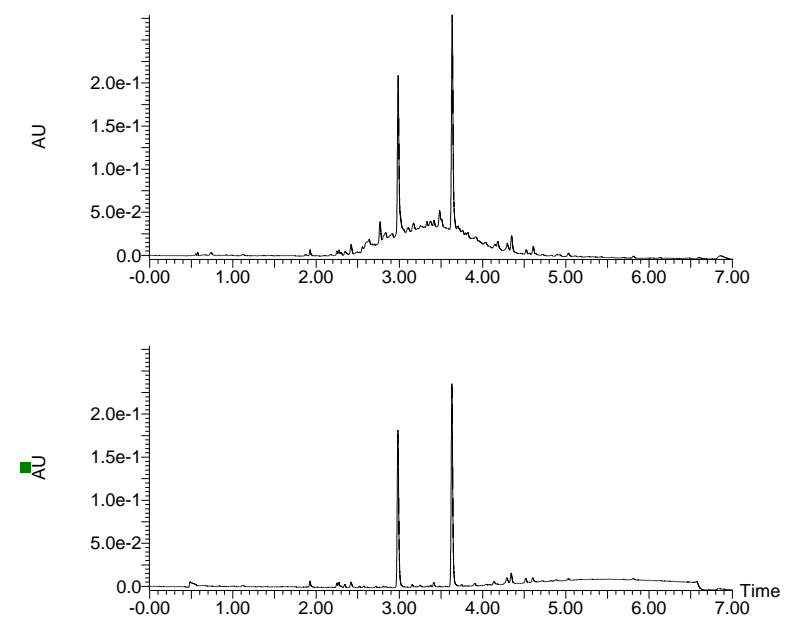

72. Aegiceras corniculatum
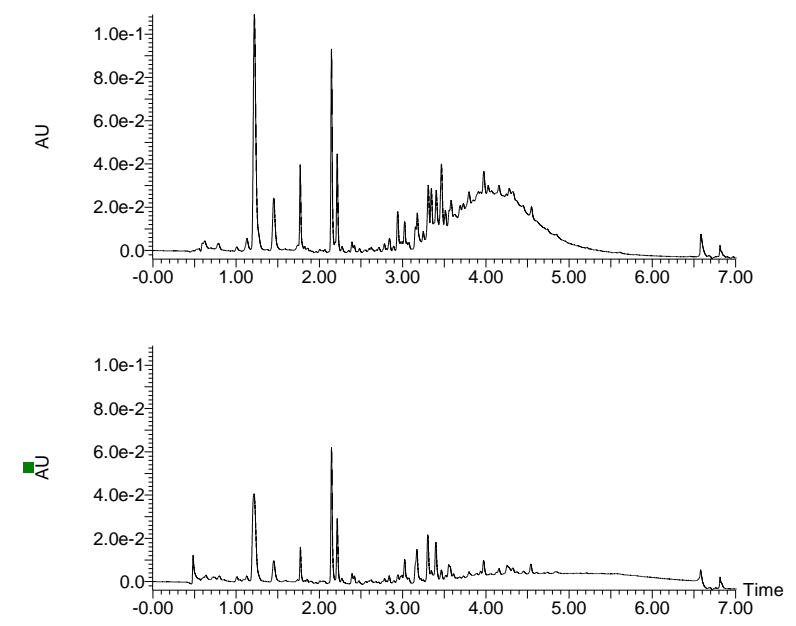

74. Cyclamen africanum
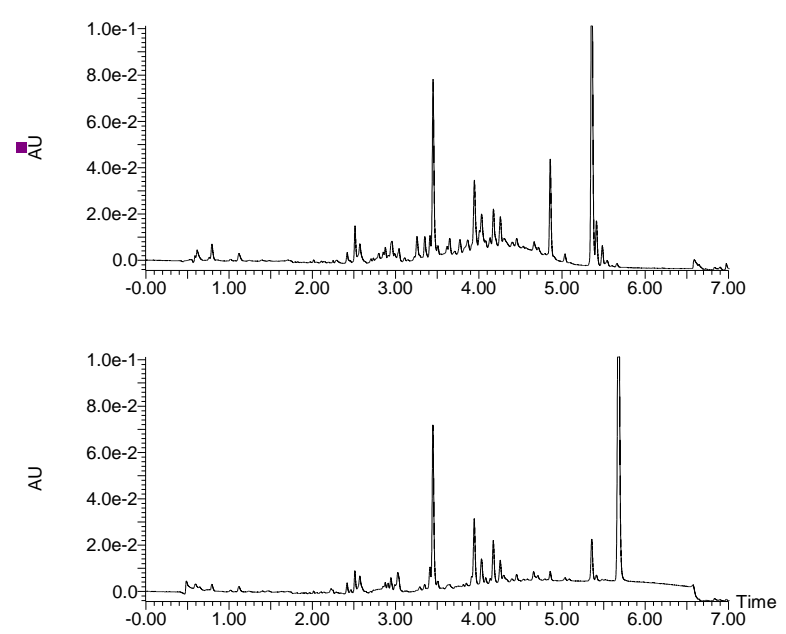

76. Pellaea ovata (leaflets)
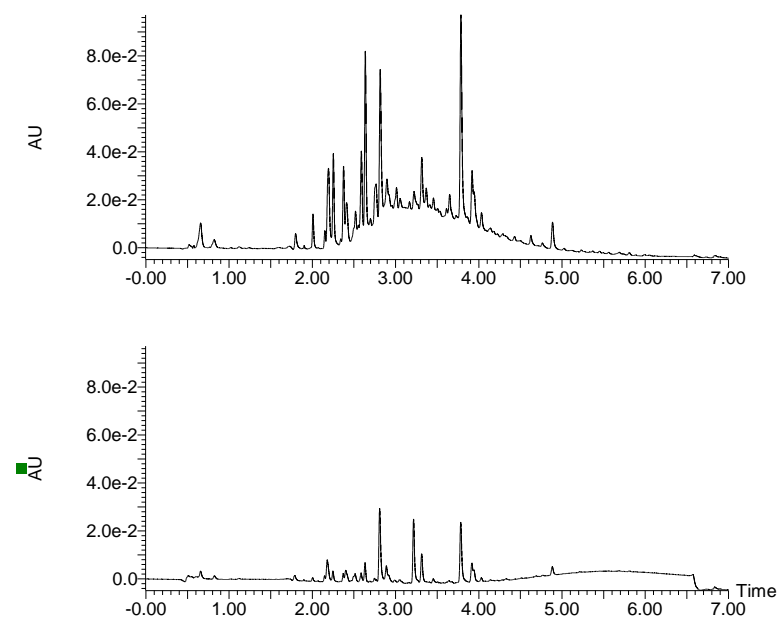
77. Rhizophora mangle
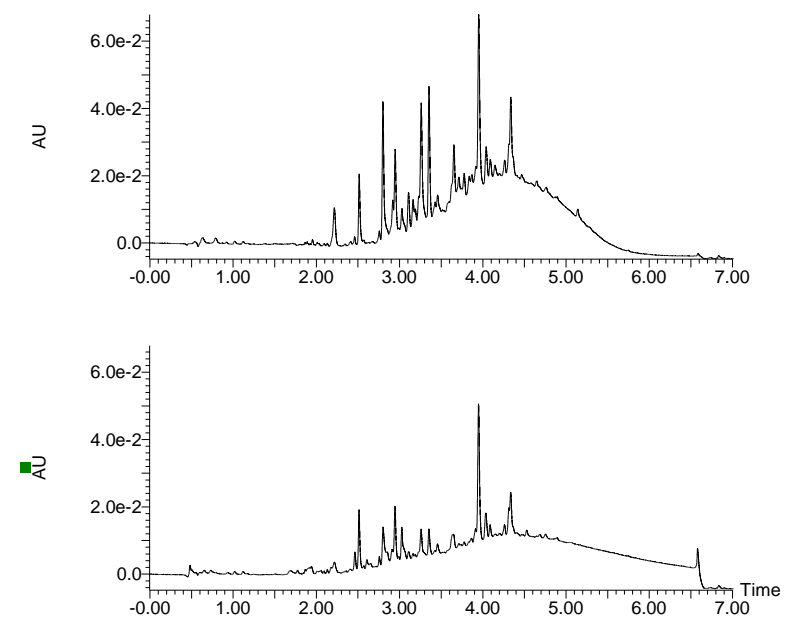

79. Osteomeles schwerinae
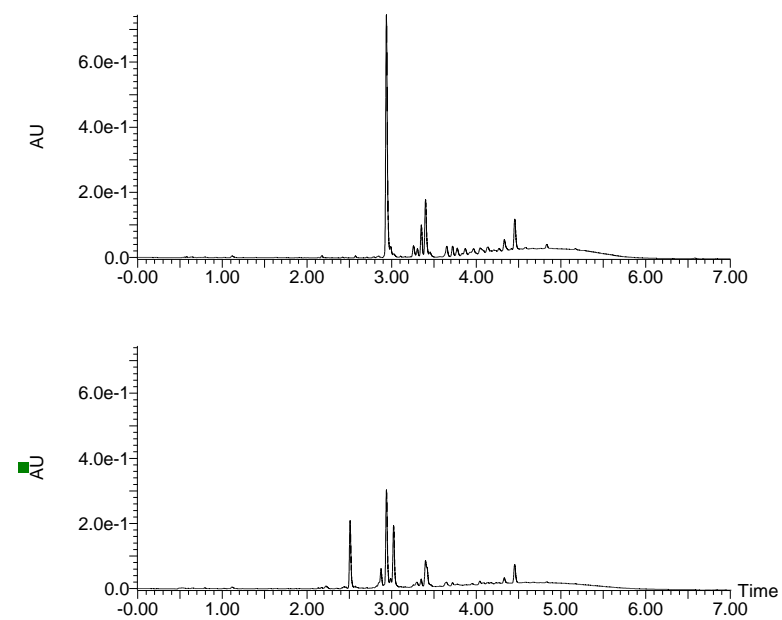

81. Rhaphiolepis indica var. umbellata
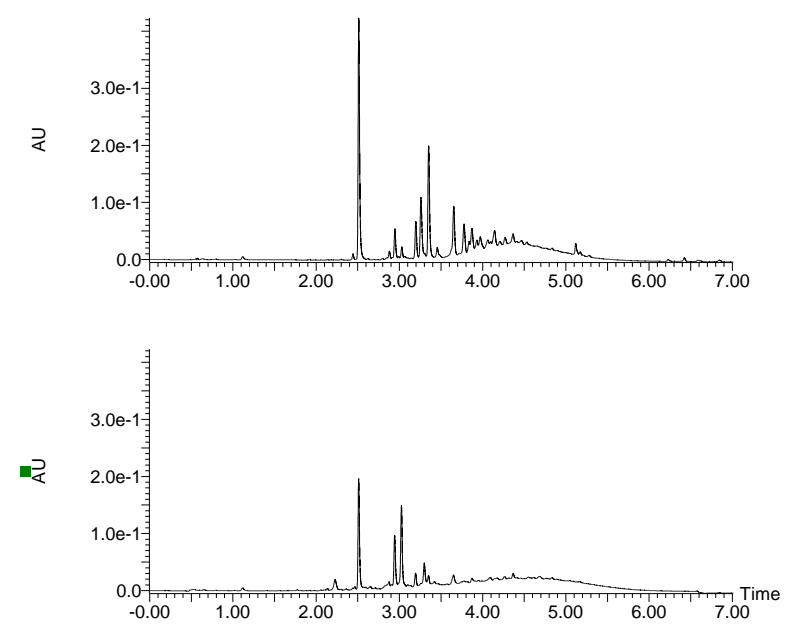

78. Eriobotrya japonica
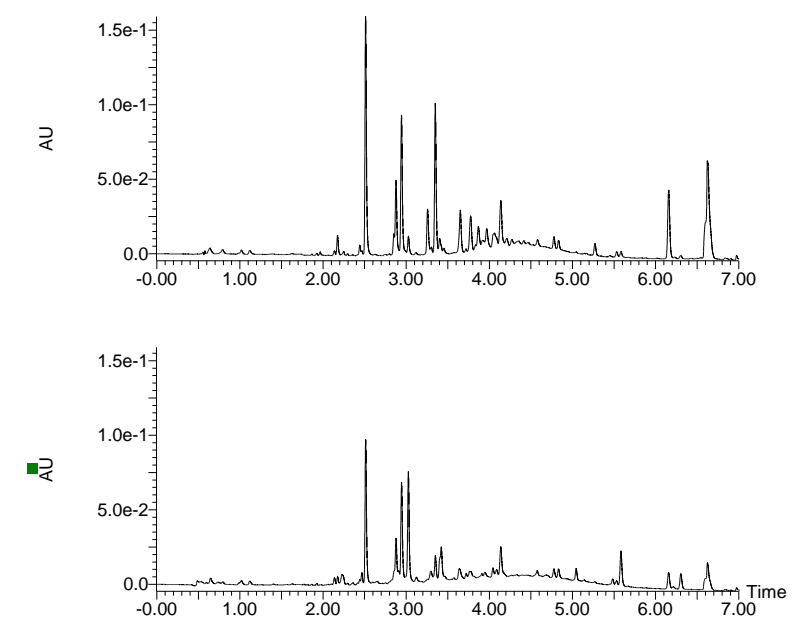

80. Osteomeles schweriniae
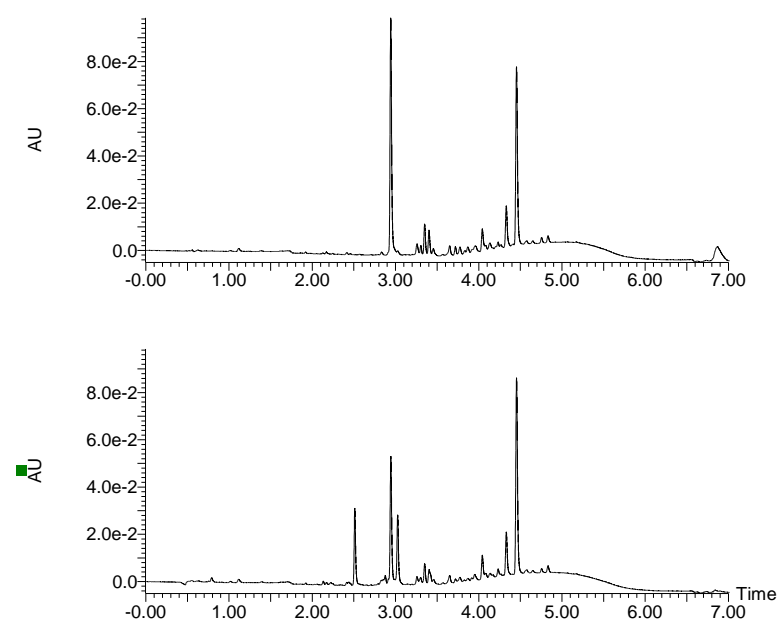

82. Coffea arabica
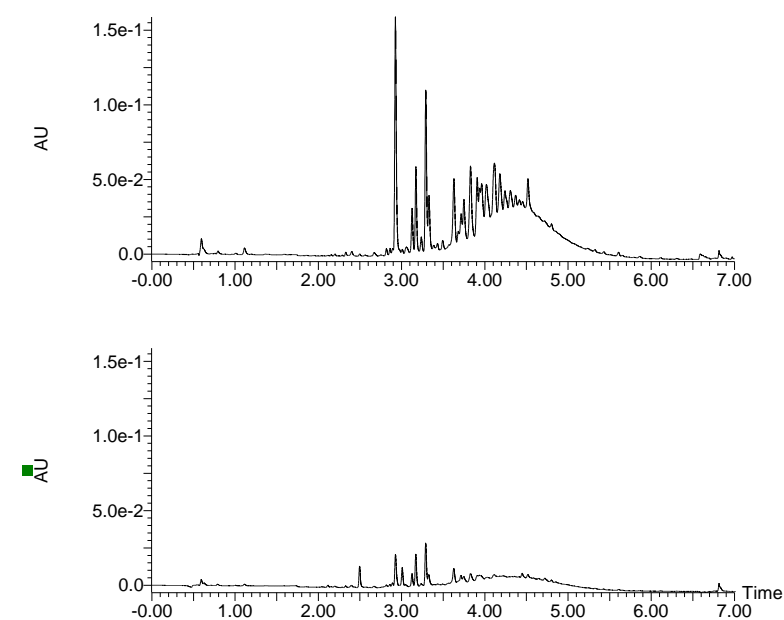


\section{Hoffmannia refulgens}
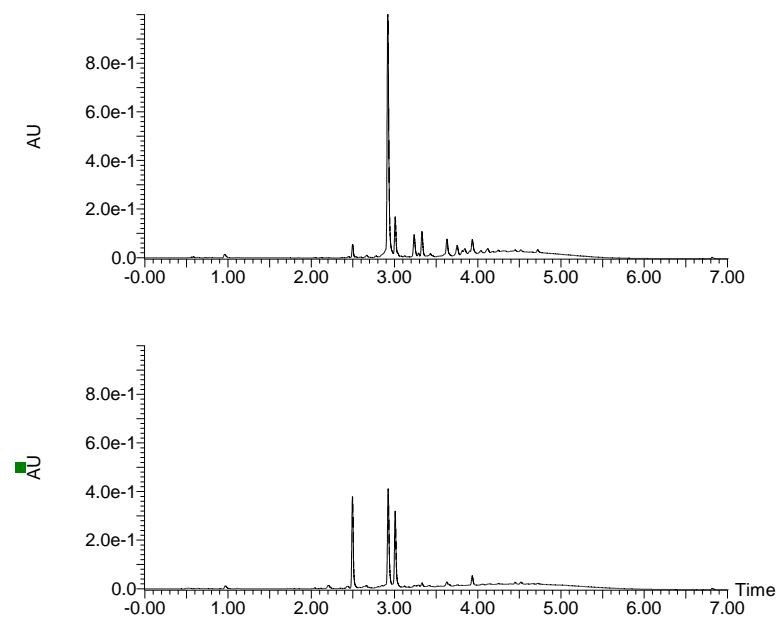

85. Ixora coccinea (flowers)
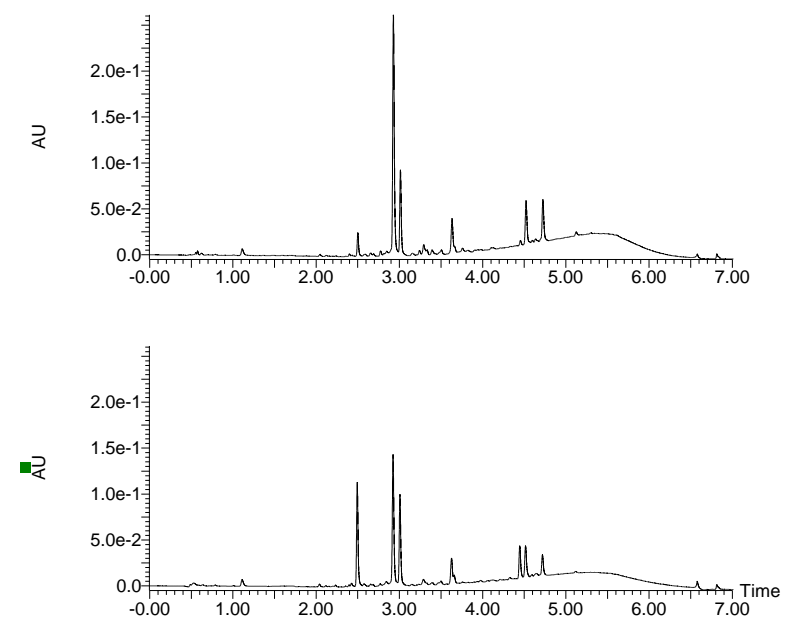

\section{Nephelium connatum}
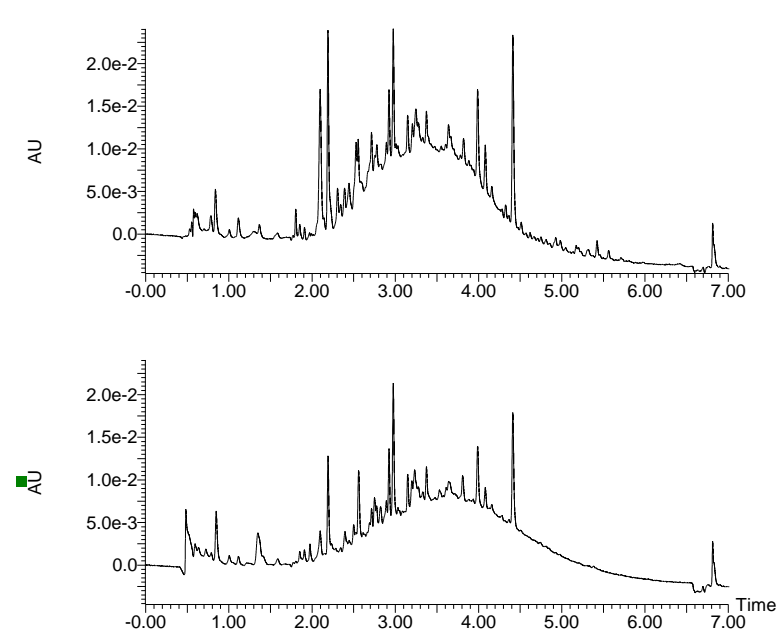

84. Ixora coccinea (leaves)
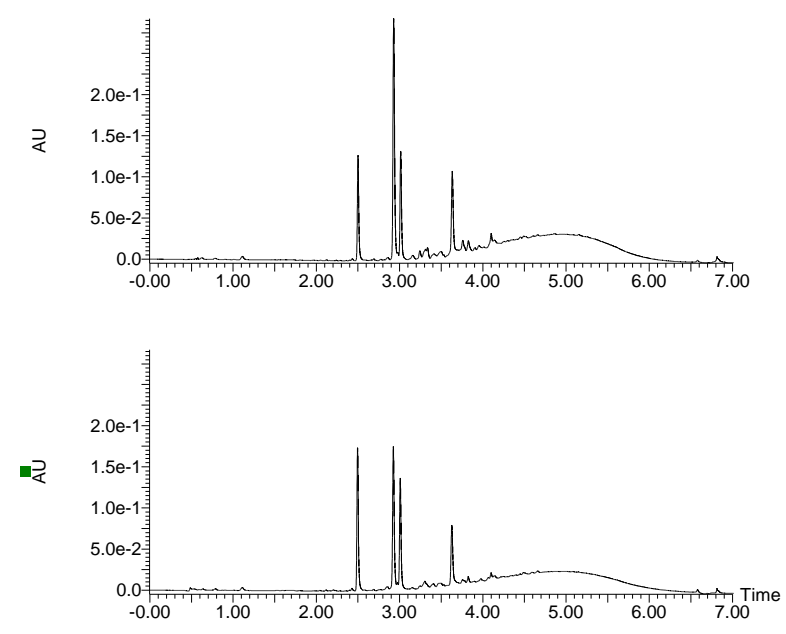

86. Dimocarpus longan
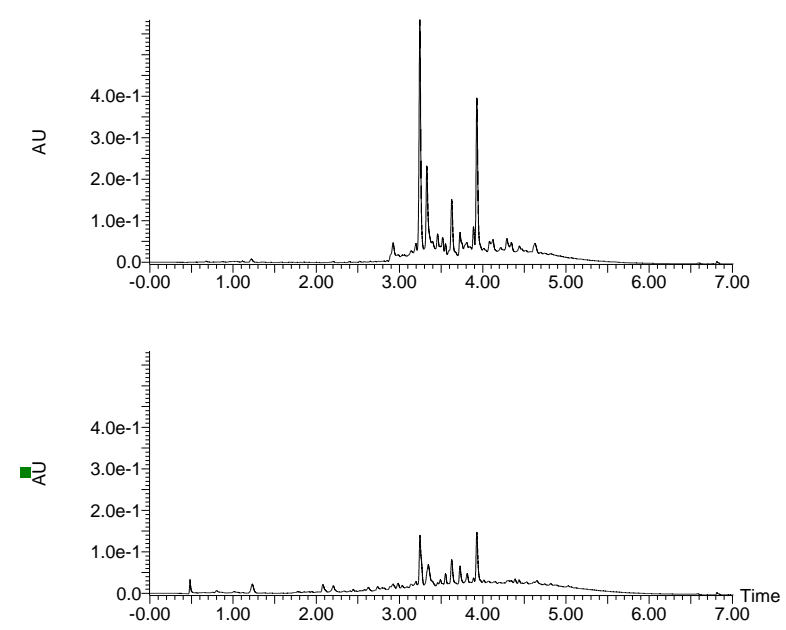

88. Sideroxylon inerme
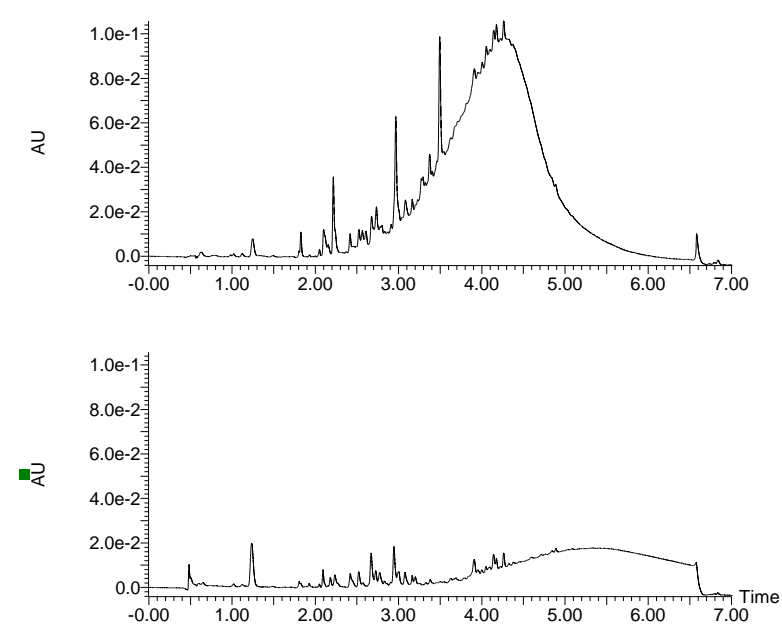
89. Sarracenia purpurea
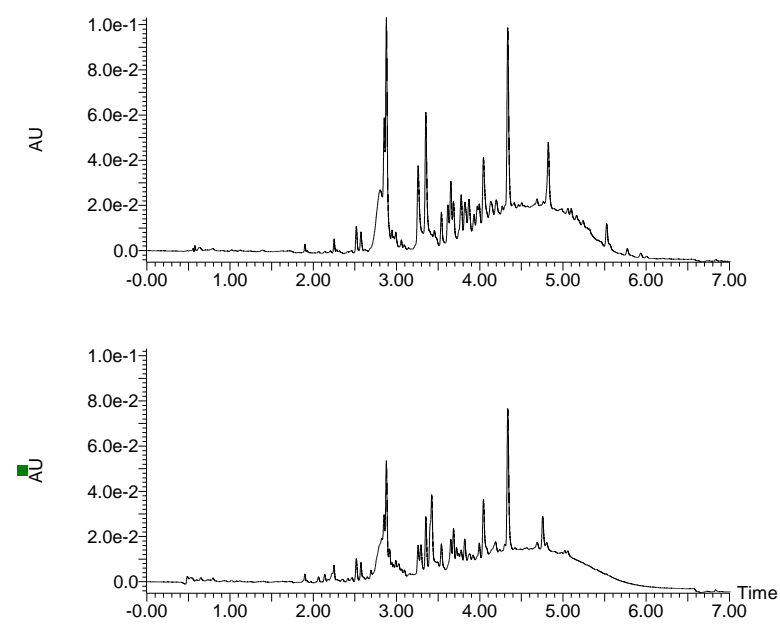

91. Strelitzia reginae (flowers)
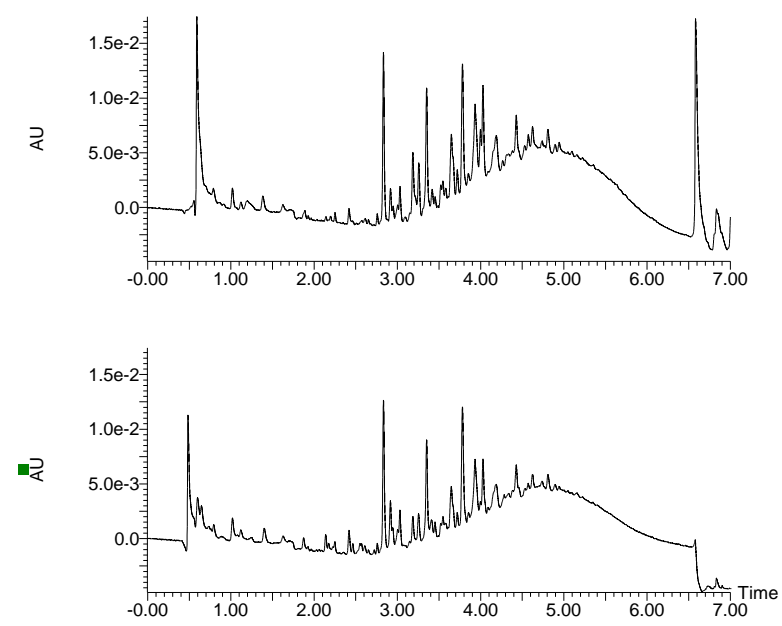

93. Camellia japonica (leaves)
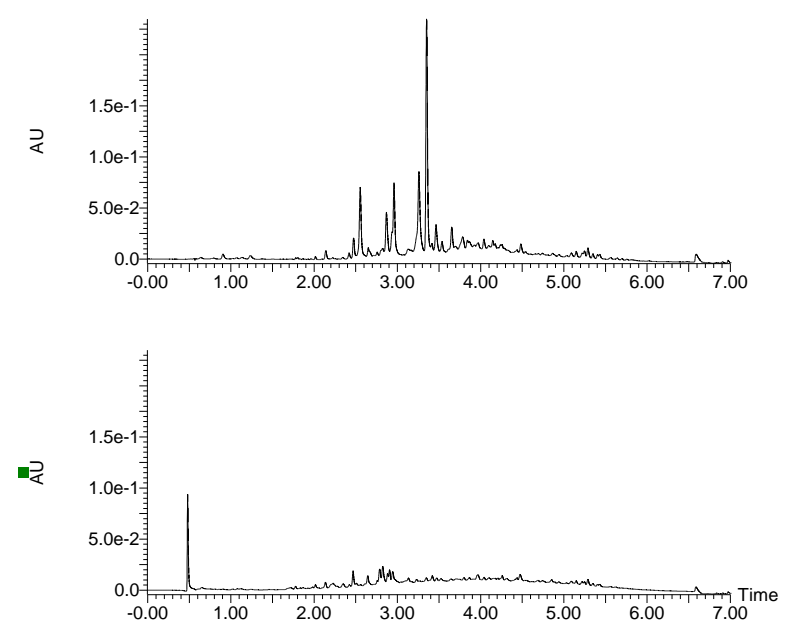

\section{Strelitzia reginae (leaves)}
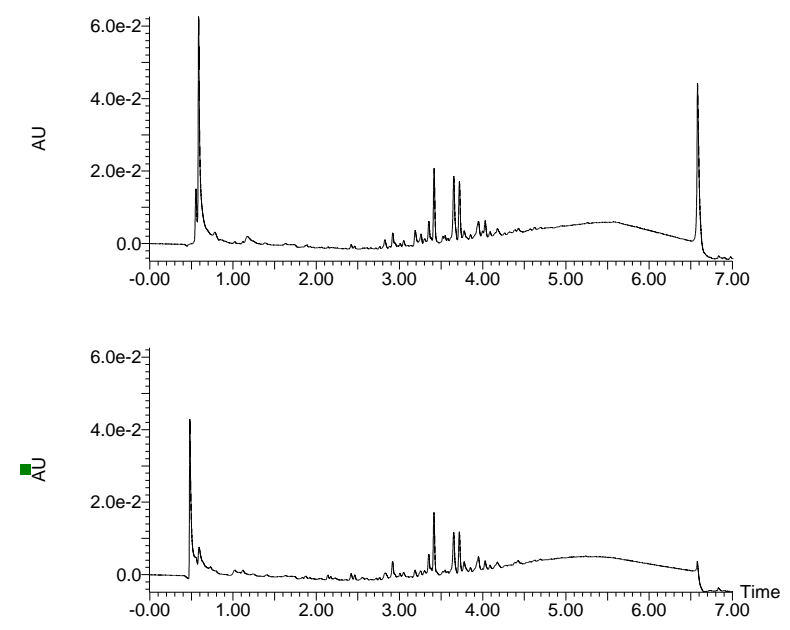

92. Tectaria macrodonta
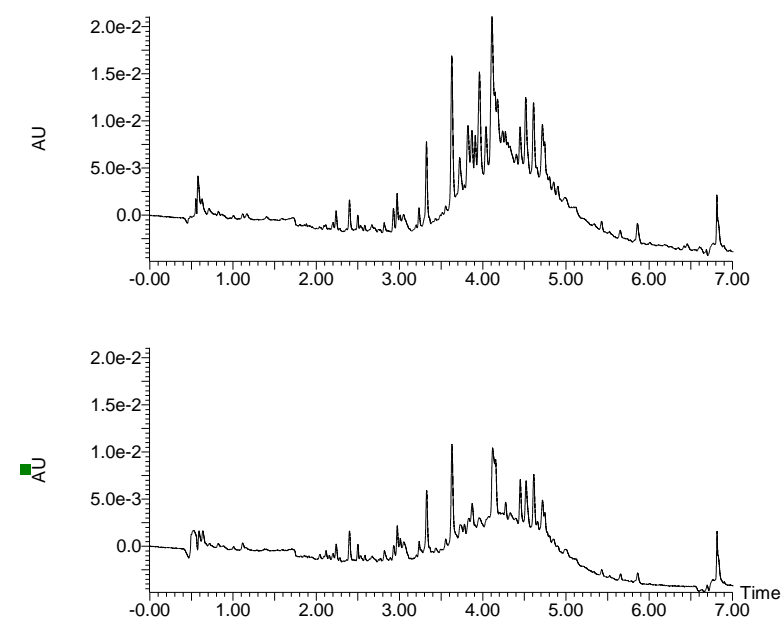

94. Camellia japonica (petals)
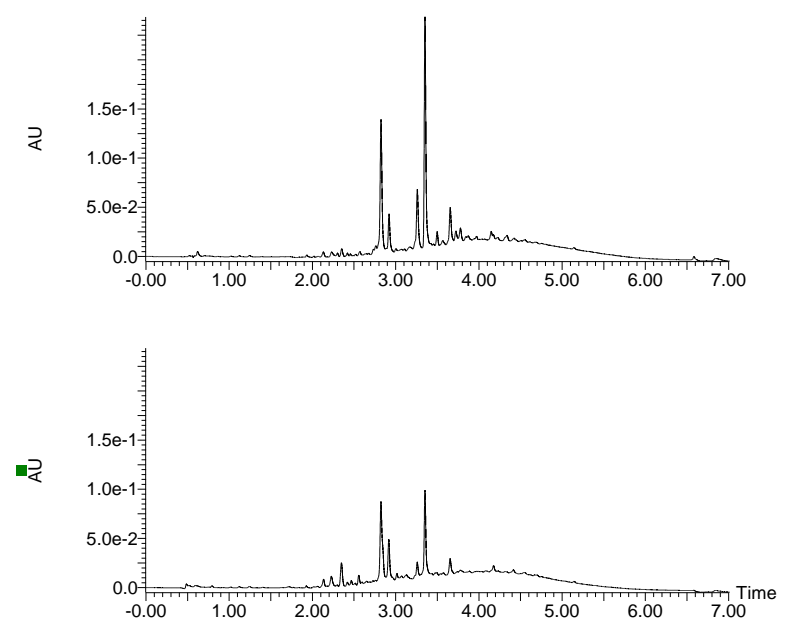
95. Cissus javana
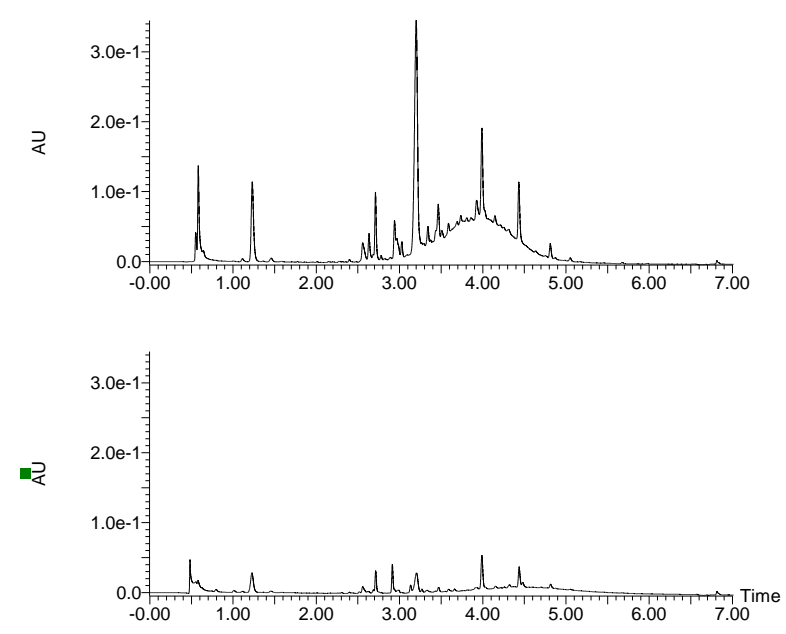

97. Rhoicissus sp.
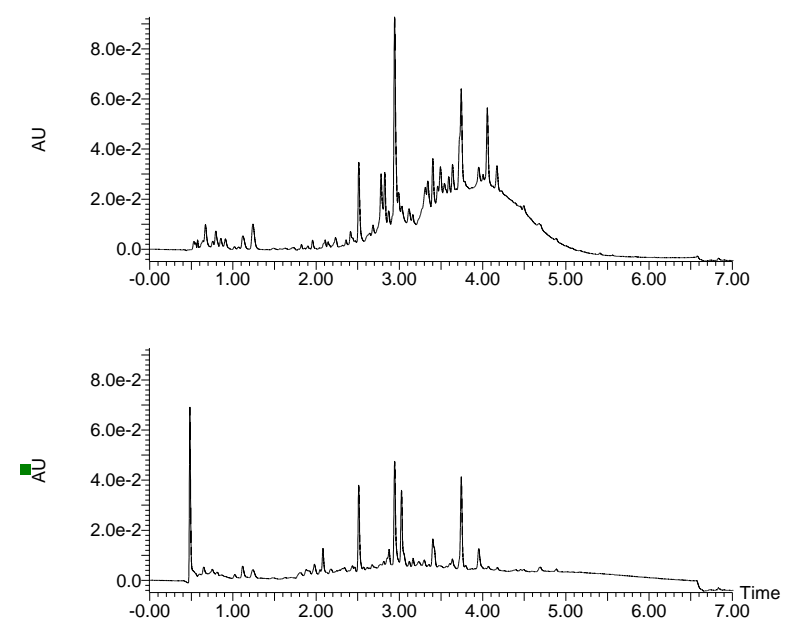

99. Macrozamia communis
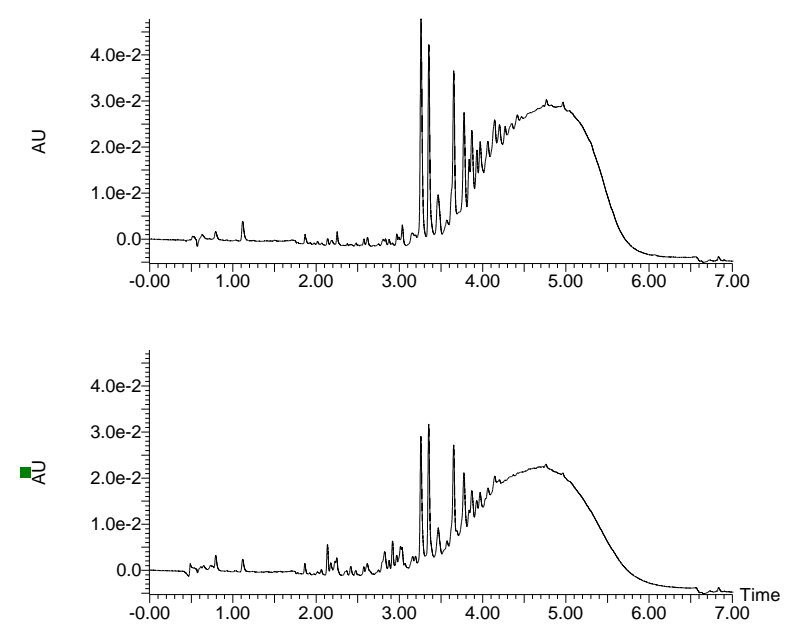

96. Leea guineense
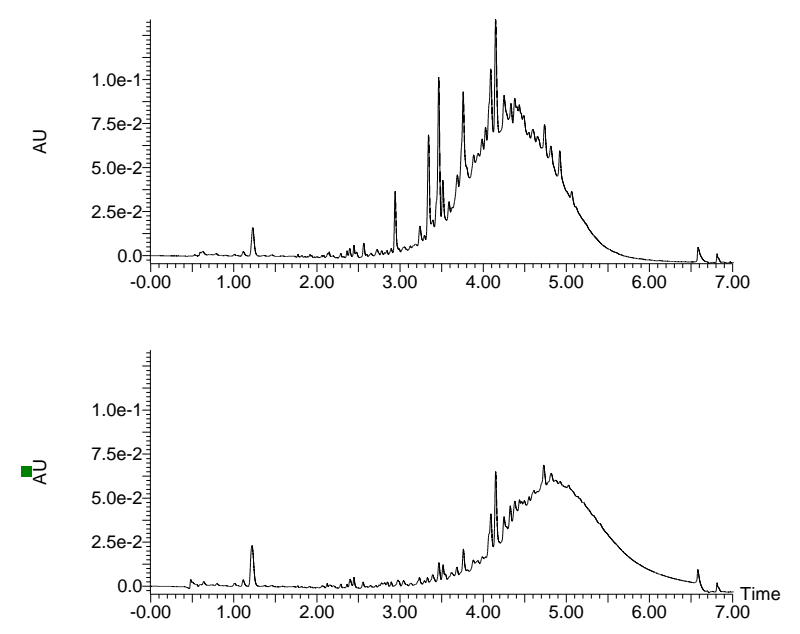

98. Encephalartos ferox
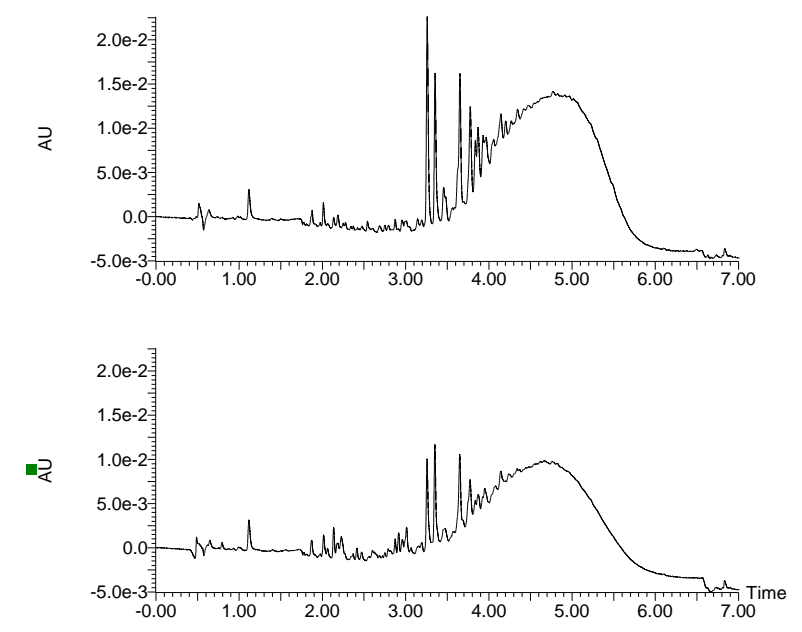

100. Zamia furfuracea
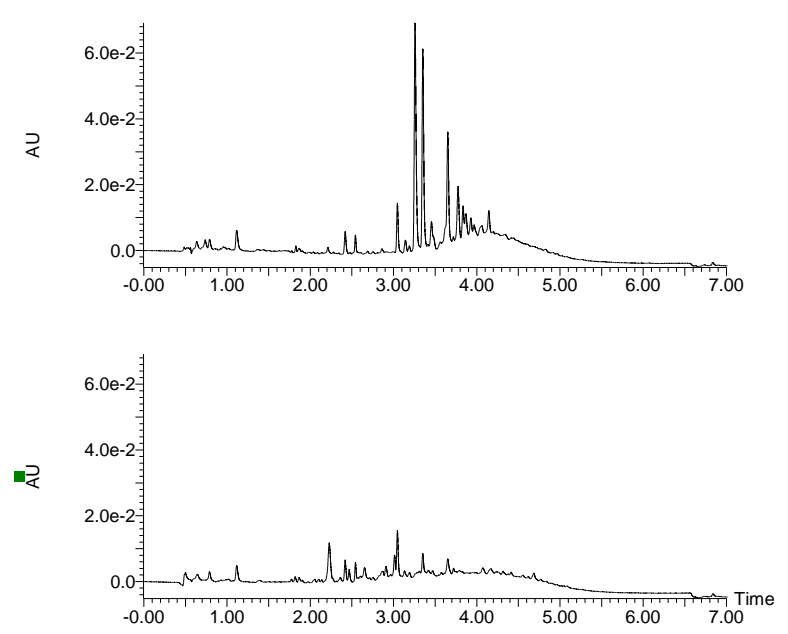
101. Alpinia purpurata
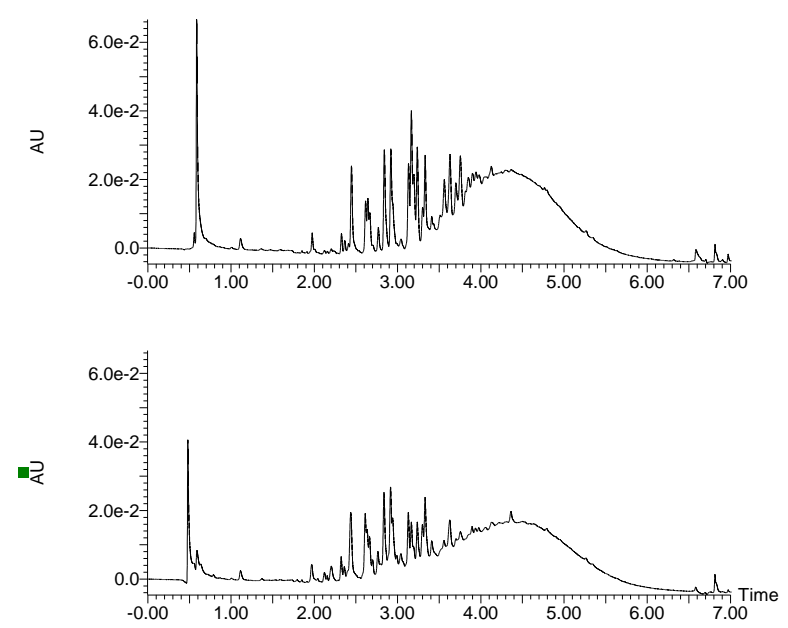

102. Elettaria cardamomun
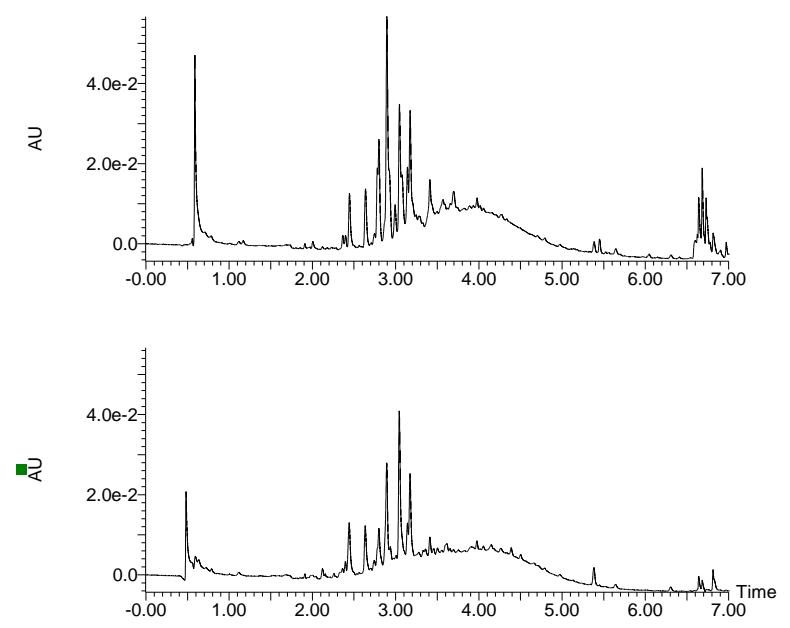
Figure S2. Correlations of different measured parameters without categorizing the 102 proanthocyanidin rich plant extracts.

Correlation of decrease in UV peak area at $280 \mathrm{~nm}$ and proanthocyanidin content by UHPLC-MS/MS due to oxidation at $\mathrm{pH} 10$

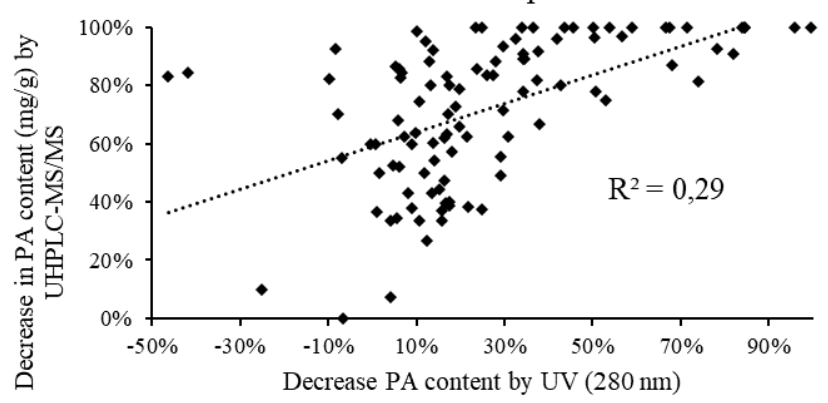

Correlation of original prodelphinidin $\%$ and decrease

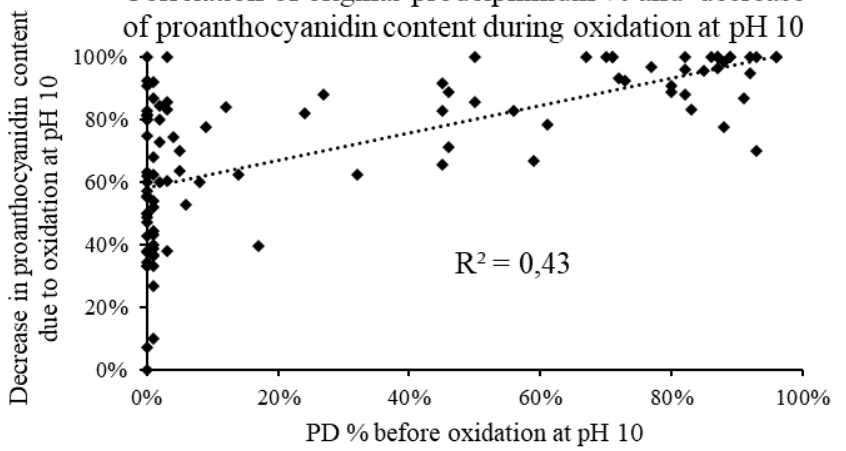

Correlation of prodelphinidin $\%$ and $\mathrm{mDP}$ before oxidation

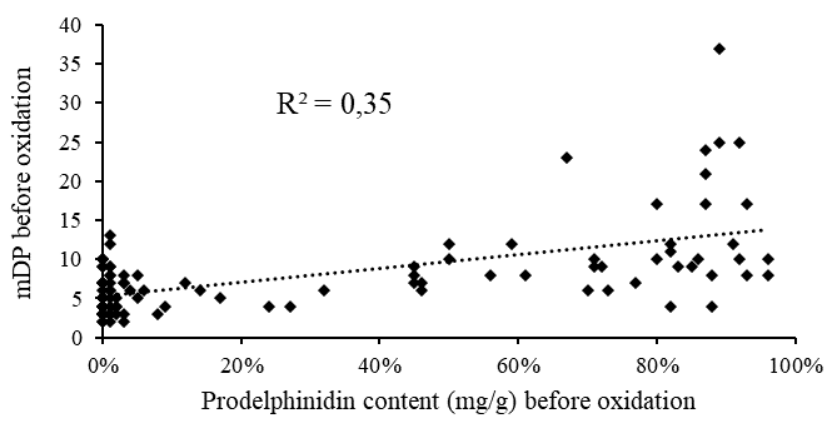

Correlation of $\mathrm{mDP}$ before oxidation and decrease of

UV peak area at $280 \mathrm{~nm}$ due to oxidation at $\mathrm{pH} 10$

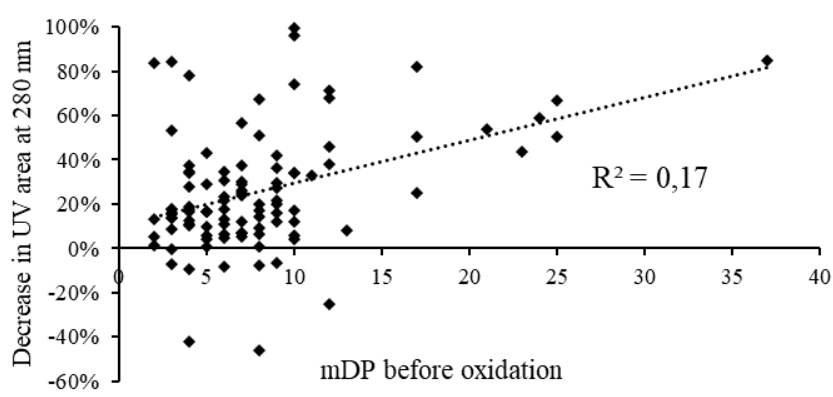

Correlation of UV peak area at $280 \mathrm{~nm}$ before and after oxidation at $\mathrm{pH} 10$
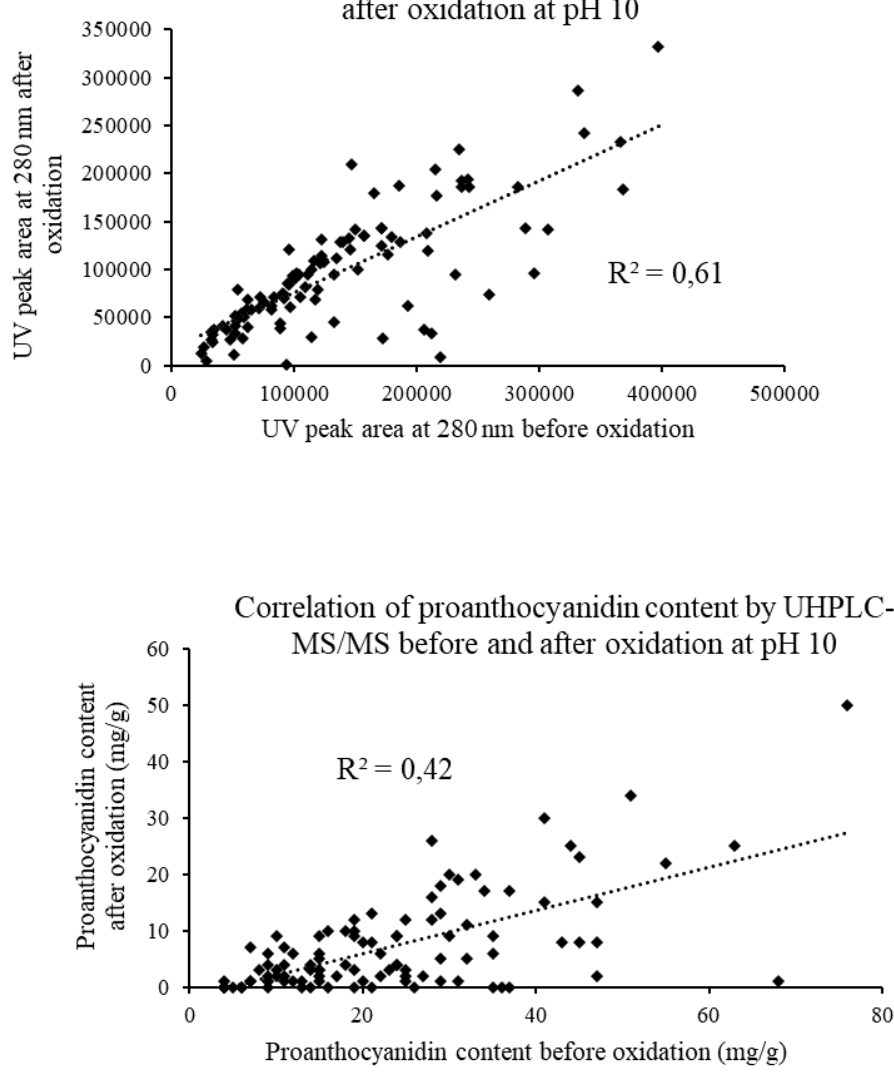

Correlation of prodelphinidin \% before oxidation and decrease in UV peak area at $280 \mathrm{~nm}$ due to oxidation at

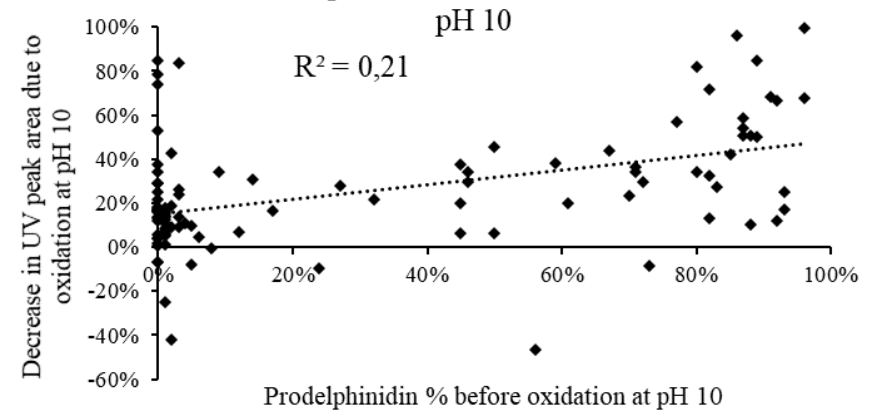

Prodelphinidin $\%$ before oxidation at $\mathrm{pH} 10$

Correlation of $\mathrm{mDP}$ and proanthocyanidin content before oxidation

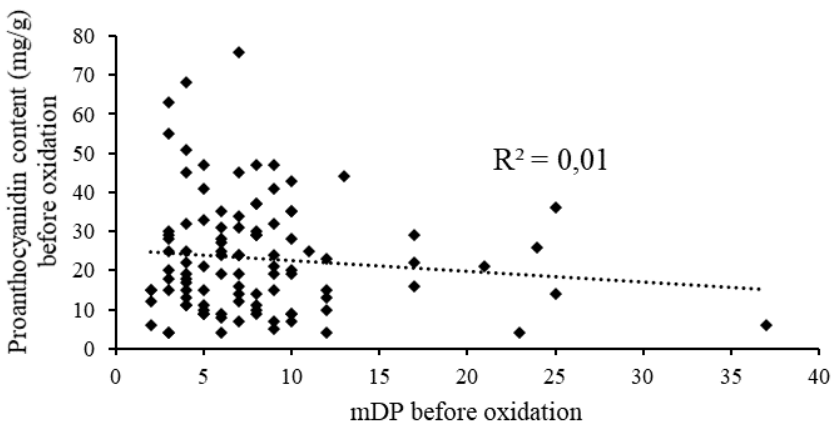


Correlation of proanthocyanidin content before

oxidation and decrease in proanthocyanidin content by UHPLC-MS/MS due to oxidation at $\mathrm{pH} 10$

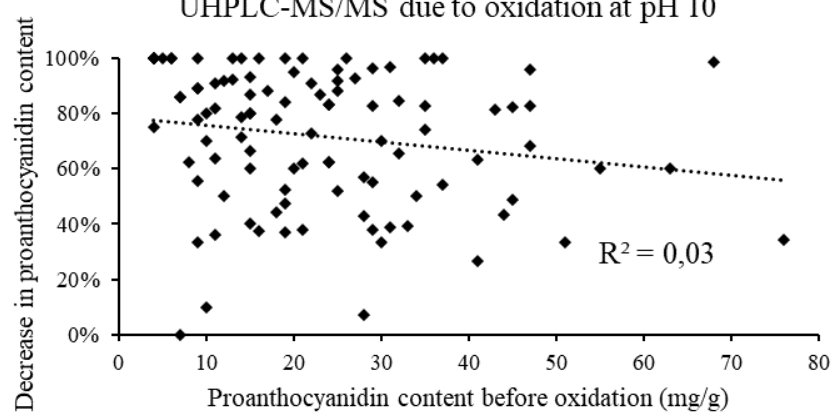

Correlation of proanthocyanidin content before oxidation and decrease in UV peak area at $280 \mathrm{~nm}$ due to oxidation at $\mathrm{pH} 10$

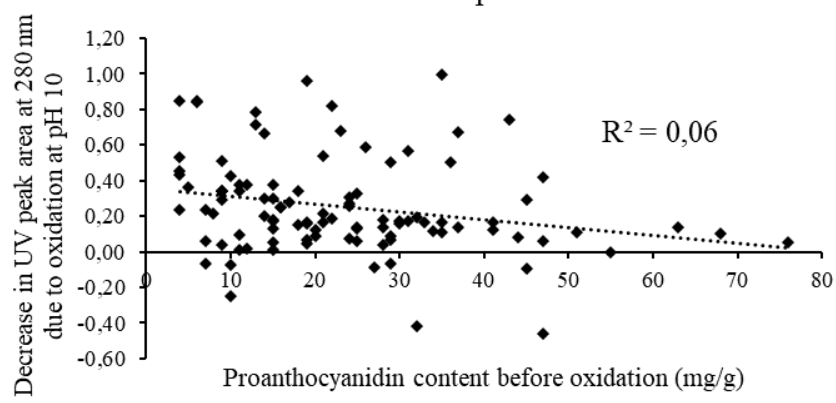

Correlation of original proanthocyanidin content and decrease in proanthocyanidin content due to oxidation

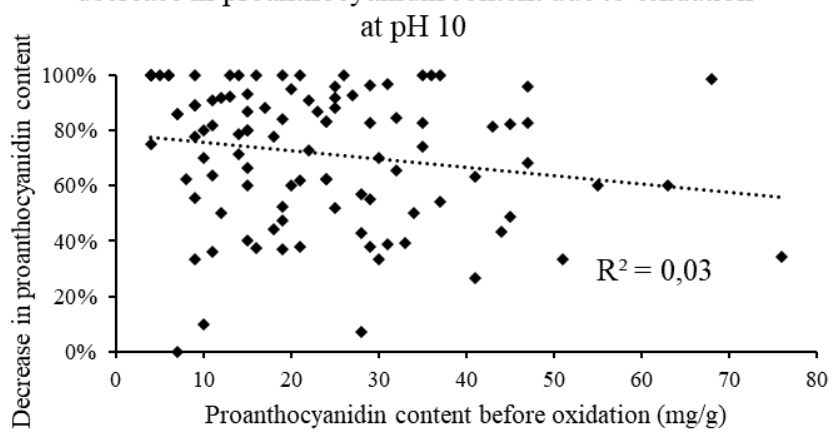


Figure S3. Correlations of different measured parameters for category A proanthocyanidin rich plant extracts.

Correlation of decrease in proanthocyanidin content by UHPLC-MS/MS and UV peak area at $280 \mathrm{~nm}$ due to oxidation at $\mathrm{pH} 10$, category A samples

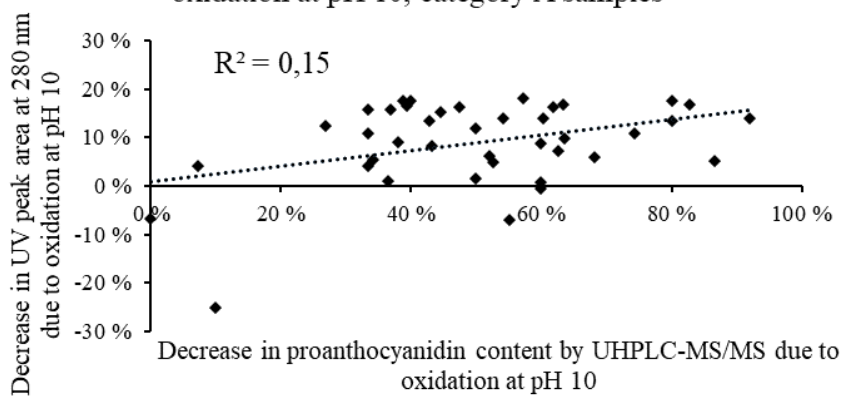

Correlation of proanthocyanidin content by UHPLCMS/MS before and after oxidation at $\mathrm{pH} 10$, category A samples

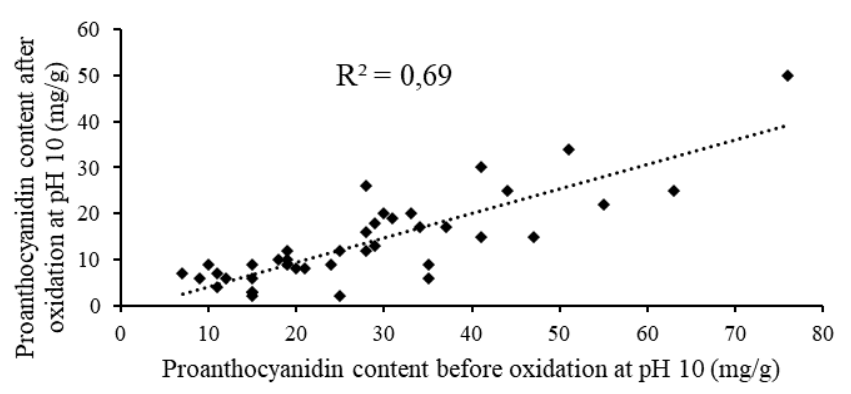

Correlation of $\mathrm{mDP}$ before oxidation and decrease in proanthocyanidin content due to oxidation at $\mathrm{pH} 10$

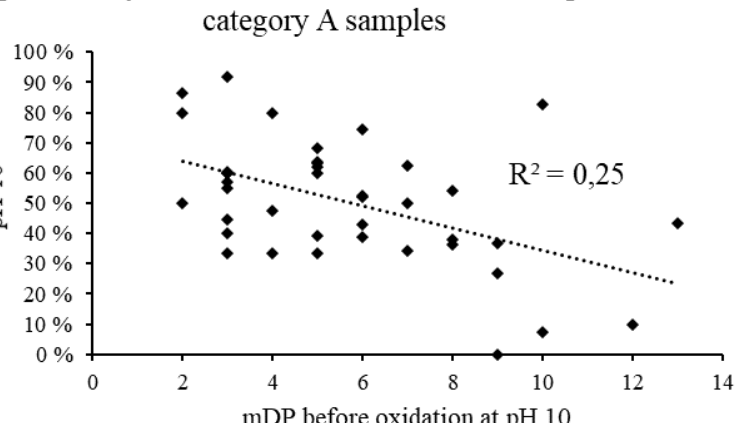

Correlation of decrease in detection of proanthocyanidins with low and high cone voltages due to oxidation at $\mathrm{pH} 10$, category A samples

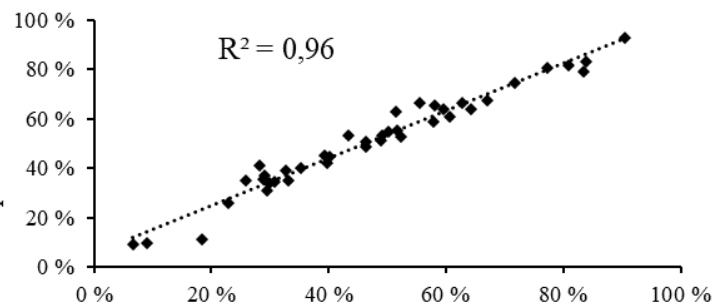

Decrease in detection of proanthocyanidins with low cone voltage $(75 \mathrm{~V})$ due to oxidation at $\mathrm{pH} 10$
Correlation of UV peak area at $280 \mathrm{~nm}$ before and after oxidation at $\mathrm{pH} 10$, category A samples

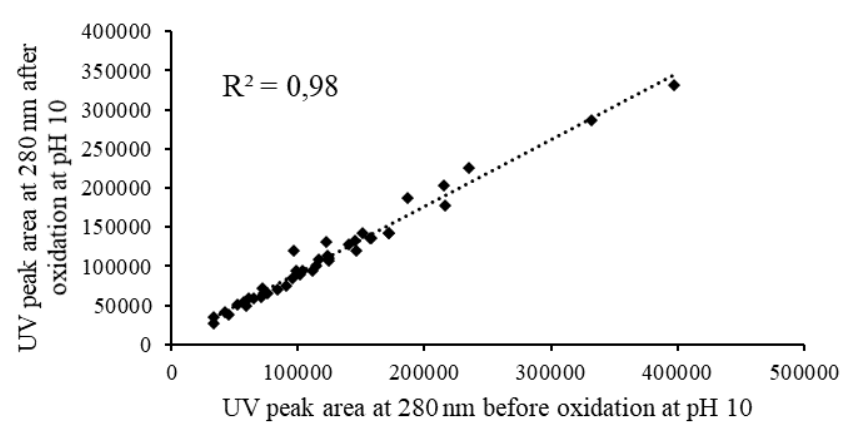

Correlation of proanthocyanidin content by UHPLCMS/MS before oxidation and decrease of 层 proanthocyanidin content by UHPLC-MS/MS due to oxidation at $\mathrm{pH} 10$, category A samples

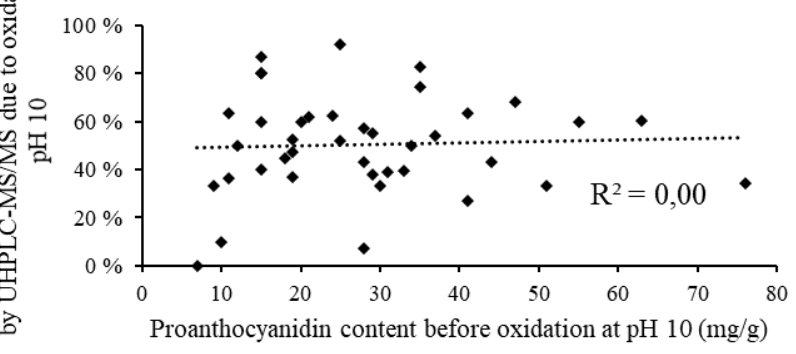

Correlation of decrease of detection of extension and terminal units due to oxidation at $\mathrm{pH} 10$, category $\mathrm{A}$

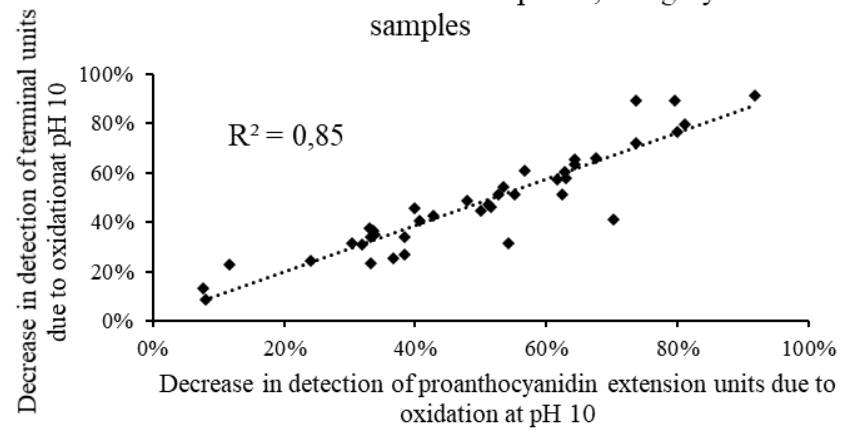
samples 
Figure S4. Correlations of different measured parameters for category B proanthocyanidin rich plant extracts.

Correlation of decrease in proanthocyanidin content by

UHPLC-MS/MS and UV peak area at $280 \mathrm{~nm}$ due to oxidation at $\mathrm{pH} 10$, category B samples

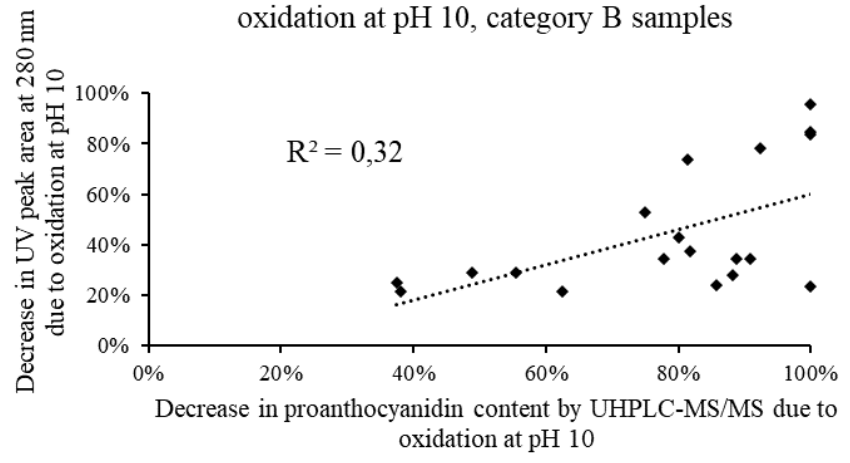

Correlation of UV peak area at $280 \mathrm{~nm}$ before and after oxidation at $\mathrm{pH} 10$, category B samples

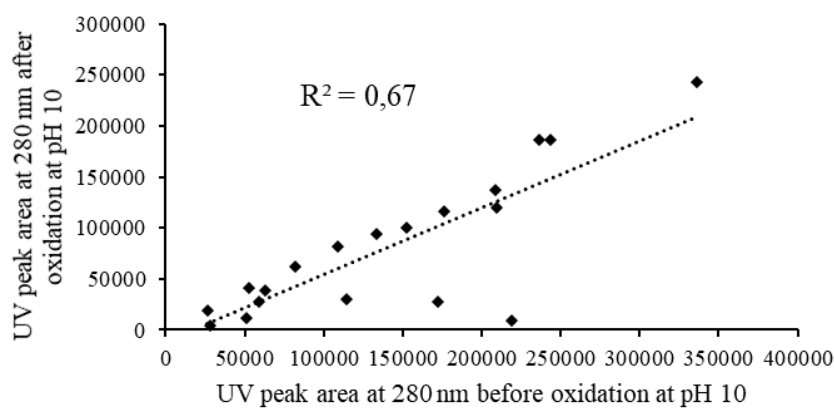

Correlation of $\mathrm{mDP}$ before oxidation and decrease in proanthocyanidin content due to oxidation at $\mathrm{pH} 10$, category B samples

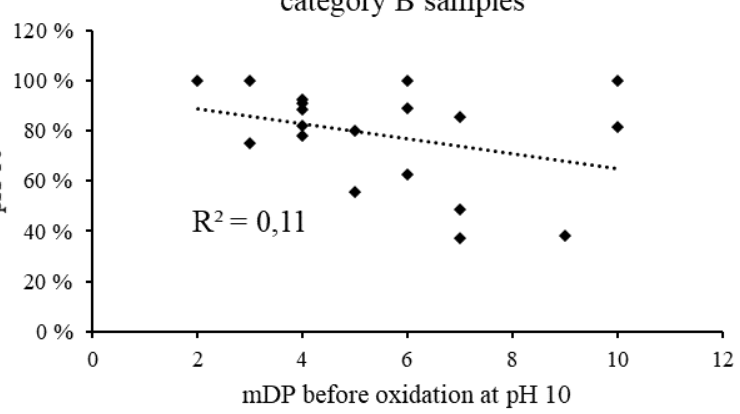

Correlation of decrease in detection of proanthocyanidins with low and high cone voltages due to oxidation at $\mathrm{pH} 10$, category $\mathrm{B}$ samples
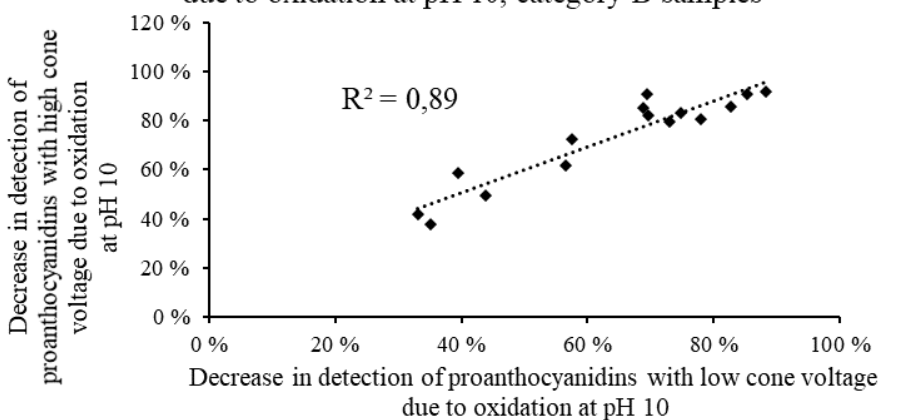

Correlation of proanthocyanidin content by UHPLCMS/MS before and after oxidation at $\mathrm{pH} 10$, category

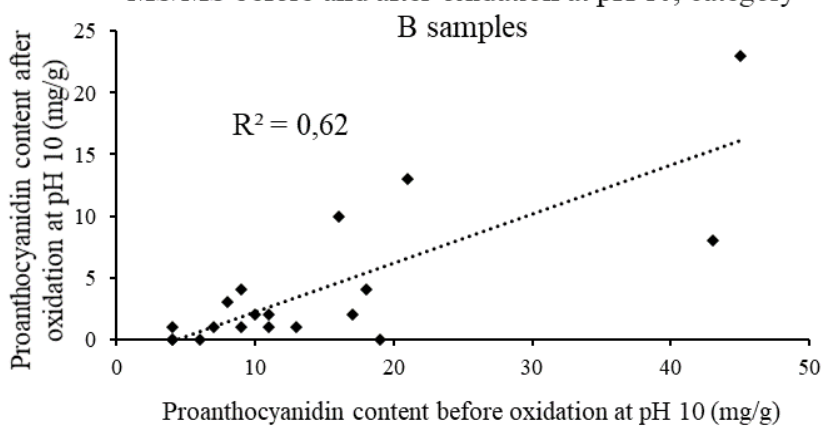

Correlation of proanthocyanidin content by UHPLCMS/MS before oxidation and decrease of proanthocyanidin content by UHPLC-MS/MS due to oxidation at $\mathrm{pH} 10$, category B samples

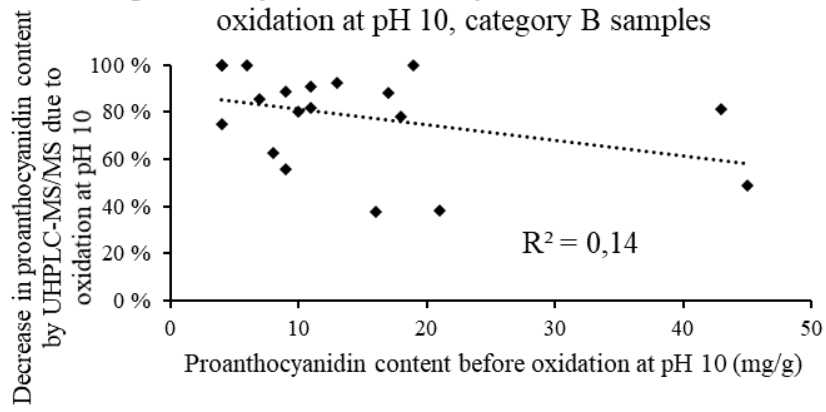

Correlation of decrease of detection of extension and terminal units due to oxidation at $\mathrm{pH} 10$, category $\mathrm{B}$

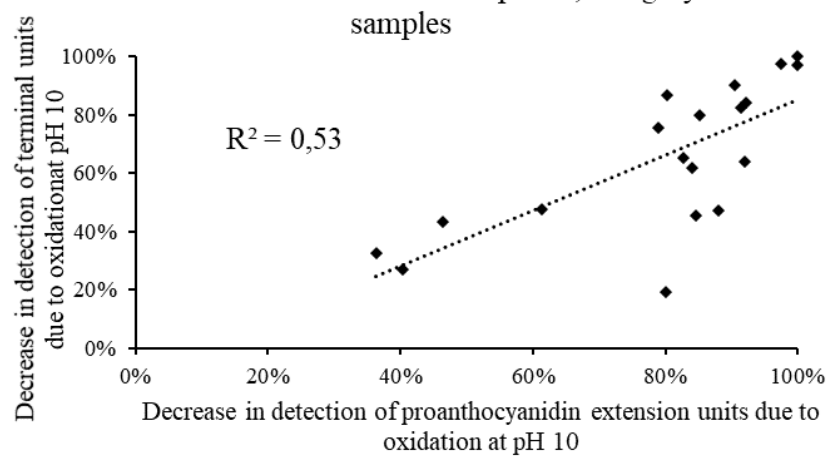


Figure S5. Correlations of different measured parameters for category C and D proanthocyanidin rich plant extracts.

Correlation of decrease in proanthocyanidin content by

UHPLC-MS/MS and UV peak area at $280 \mathrm{~nm}$ due to

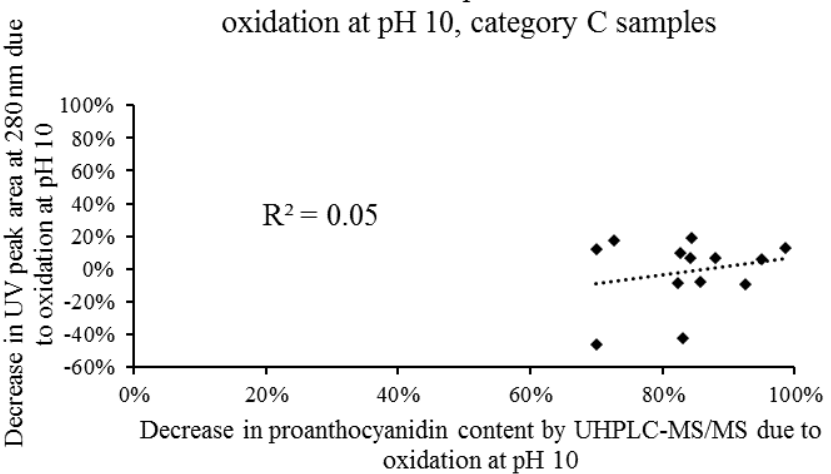

Correlation of proanthocyanidin content by UHPLCMS/MS before and after oxidation at $\mathrm{pH} 10$, category

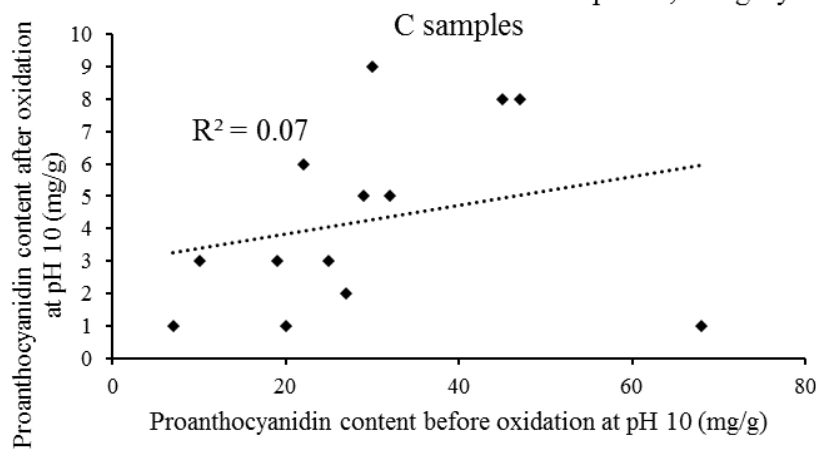

Correlation of UV peak area at $280 \mathrm{~nm}$ before and after oxidation at $\mathrm{pH} 10$, category $\mathrm{C}$ samples

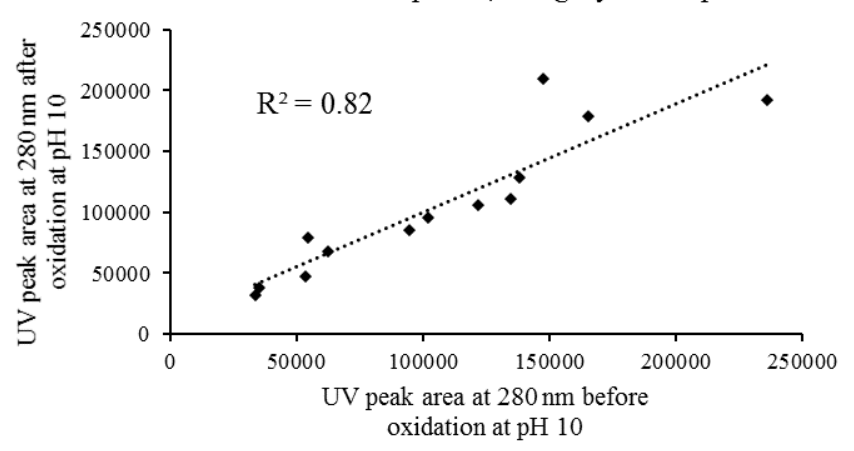

Correlation of decrease in proanthocyanidin content by

UHPLC-MS/MS and UV peak area at $280 \mathrm{~nm}$ due to oxidation at $\mathrm{pH} 10$, category $\mathrm{D}$ samples

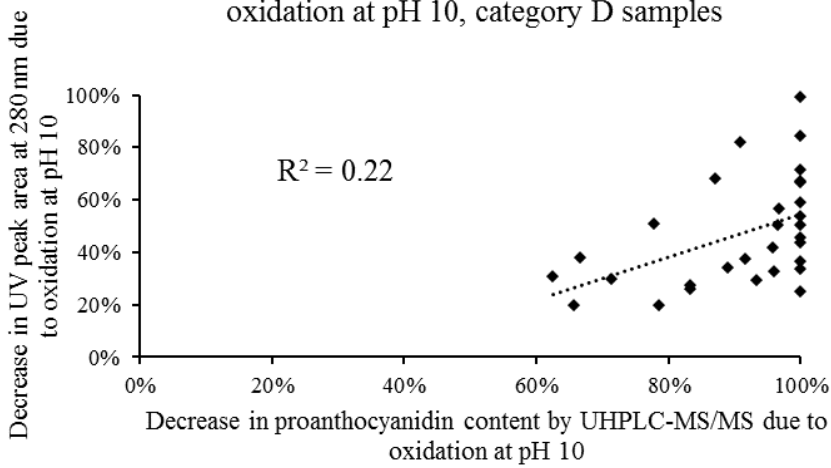

Correlation of proanthocyanidin content by UHPLCMS/MS before and after oxidation at $\mathrm{pH} 10$, category

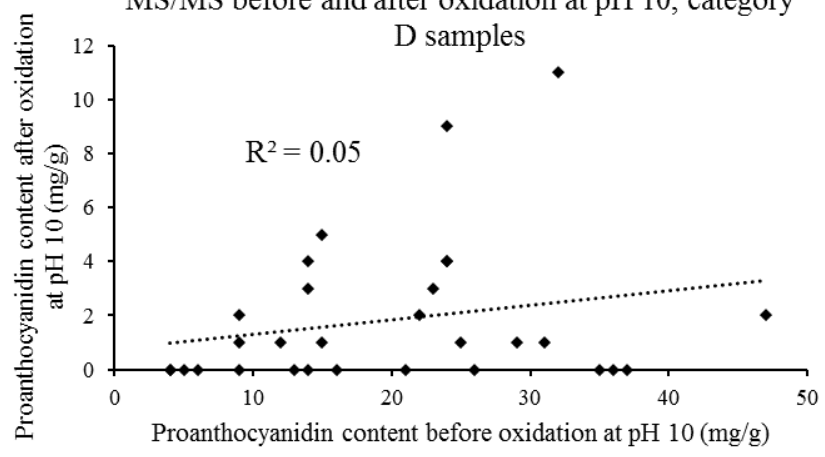

Correlation of UV peak area at $280 \mathrm{~nm}$ before and after oxidation at $\mathrm{pH} 10$, category D samples

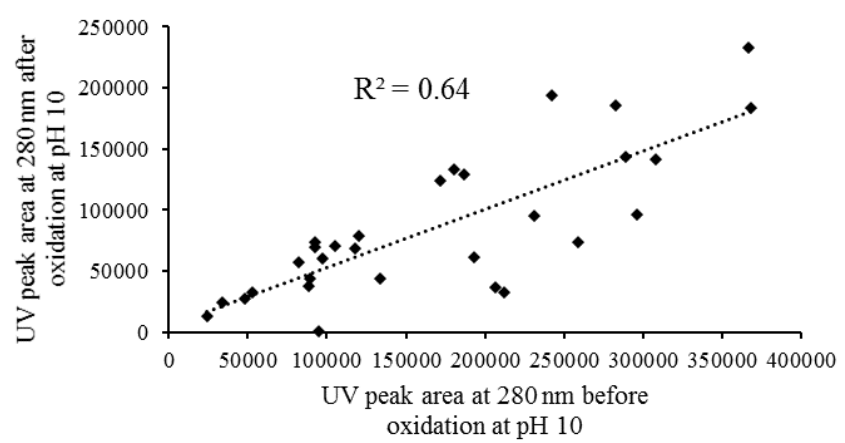

